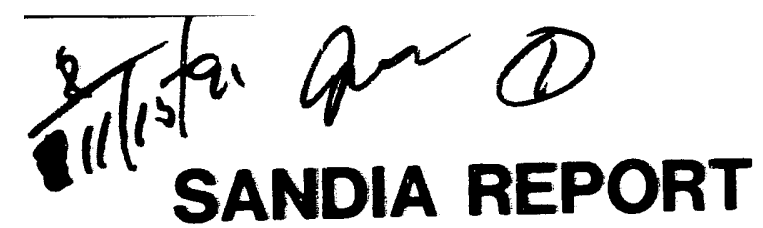

SAND90-0294 $\cdot$ UC-704

Unimited Release

Printed November 1991

\title{
An Experimental/Analytical Comparison of Strains in Encapsulated Assembilies
}

T. R. Guess, S. N. Burchett

Prepared by

Sandia National Laboratories

Albuquerque, New Mexico 87185 and Livermore, California 94550

for the United States Department of Energy

under Contract DE-ACO4-760P00789

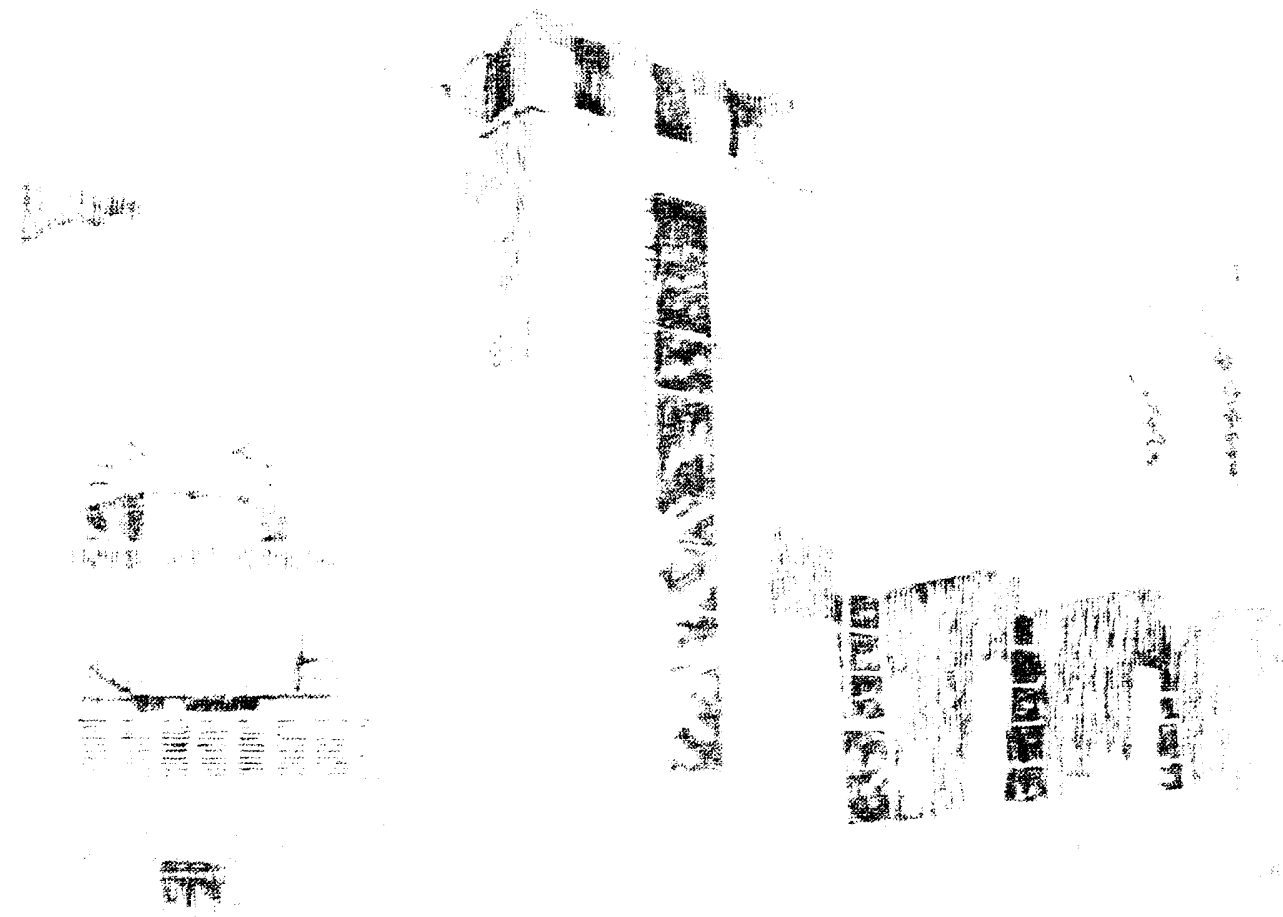


Issued by Sandia National Laboratories, operated for the United States Department of Energy by Sandia Corporation.

NOTICE: This report was prepared as an account of work sponsored by an agency of the United States Government. Neither the United States Government nor any agency thereof, nor any of their employees, nor any of their contractors, subcontractors, or their employees, makes any warranty, express or implied, or assumes any legal liability or responsibility for the accuracy, completeness. or usefulness of any information, apparatus, product, or process disclosed, or represents that its use would not infringe privately owned rights. Reference herein to any specific commercial product, process, or service by trade name, trademark, manufacturer, or otherwise, does not necessarily constitute or imply its endorsement, recommendation, or favoring by the United States Government, any agency thereof or any of their contractors or subcontractors. The views and opinions expressed herein do not necessarily state or reflect those of the United States Government, any agency thereof or any of their contractors.

Printed in the United States of America. This report has been reproduced directly from the best available copy.

Available to DOE and DOE contractors from

Office of Scientific and Technical Information

PO Box 6?

Oak Ridge. TN 378.31

Prices available from (615) 576-8401, FTS 626-8401

Available to the public from

National Technical Information Service

US Department of Commerce

5285 Port Royal Rd

Springfield, VA 22151

NTIS price codes

Printed copy: An3

Microfiche copy: A01 


\title{
An Experimental/Analytical Comparison of Strains in Encapsulated Assemblies
}

\author{
T. R. Guess \\ Organic Materials Division \\ S. N. Burchett \\ Engineering and Structural Mechanics Division \\ Sandia National Laboratories \\ Albuquerque, New Mexico 87185
}

\begin{abstract}
A combined experimental and analytical study of strains developed in encapsulated assemblies during casting. curing and thermal excursions is described. The experimental setup, designed to measure in situ strains, consisted of thin, closed-end, Kovar ${ }^{*}$ tubes that were instrumented with strain gages and thermocouples before being over-cast with a polymeric encapsulant. Four bisphenol $A$ (three diethanolamine cured and one anhydride cured) epoxy-based materials and one urethane elastomeric material were studied. After cure of the encapsulant, tube strains were measured over the temperature range of $-55^{\circ} \mathrm{C}$ to $90^{\circ} \mathrm{C}$. The thermal excursion experiments were then numerically modeled using finite element analyses and the computed strains were compared to the experimental strains. The predicted strains were over estimated (conservative) when a linear, elastic. temperature-dependent material model was assumed for the encapsulant and the strcss free temperature $T_{i}$ was assumed to correspond to the cure temperature $T_{c}$ of the encapsulant. Very good agreement was obtained with linear elastic calculations provided that the stress free temperature corresponded to the onset of the glassy-to-rubbery transition range of the encapsulant. Finally, excellent agreement was obtained in one of the materials (828/DEA) when a viscoelastic material model was utilized and a stress free temperature corresponding to the cure temperature was assumed.
\end{abstract}

- "hovar" is a registered trademark of Carpenter Technology Corporation 


\section{Contents}

Introduction . . . . . . . . . . . . . . . . . . . . . . . . . . . . .

Experimental Procedure

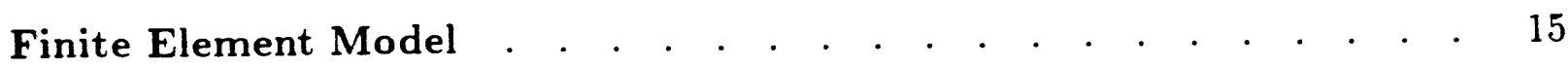

Encapsulating Materials . . . . . . . . . . . . . . . . . . . 17

Results and Discussion . . . . . . . . . . . . . . . . . . . 21

Validation of Test Procedure . . . . . . . . . . . . . . . . . . . . . 21

Potting and Cure . . . . . . . . . . . . . . . . . . . . . . . . . . . 21

Thermal Excursions . . . . . . . . . . . . . . . . . . . . . 22

hovar Encapsulated in $828 / \mathrm{DEA}$. . . . . . . . . . . . . . . . . 22

Kovar Encapsulated in 828/CTBN/DEA . . . . . . . . . . . . 29

hovar Encapsulated in $828 / \mathrm{CTBN} / \mathrm{GMB} / \mathrm{DEA}$. . . . . . . . . . . . 29

hovar Encapsulated in SRIR . . . . . . . . . . . . . . . . . 29

Kovar Encapsulated in Adiprene L-100/BD/TMP . . . . . . . . . 29

Comments . . . . . . . . . . . . . . . . . . . . . . . . 33

Summary .

References . . . . . . . . . . . . . . . . . . . . . . . . . . . .

Acknowledgments . . . . . . . . . . . . . . . . . . . . . . . . . . . 


\section{Tables}

1 Materials Studied and Governing Process Specifications . . . . . . . 17

2 Temperature-Dependent Material Properties . . . . . . . . . . 20

3 Room Temperature Residual Strains in Kovar Tube Following Cure of Encapsulant . . . . . . . . . . . . . . . . . . . . . . 23 


\section{Figures}

1 Analysis of Encapsulated Assemblies . . . . . . . . . . . . . . 10

2 Experimental Configuration . . . . . . . . . . . . . . . . 14

3 Finite Element Idealization of Experiment . . . . . . . . . . . 15

4 Dynamic Shear Modulus Measured at $2 \mathrm{kHz}$. . . . . . . . . . 18

5 Free Expansion of Non-encapsulated Kovar Tube . . . . . . . . . 22

$6828 /$ DEA - Potting and Cure Strains . . . . . . . . . . . . . . . 23

T 828/DEA - Axial Strain in Kovar - Elastic Analysis - Stress Free Temper-

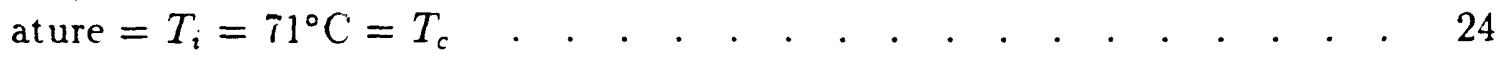

8 828/DEA - Hoop Strain in Kovar - Elastic Analysis - Stress Free Temperature $=T_{i}=71^{\circ} \mathrm{C}=T_{c}$. $.4 . \quad . \quad . \quad . \quad . \quad . \quad . \quad . \quad . \quad . \quad . \quad . \quad . \quad . \quad 24$

$9828 / \mathrm{DEA}$ - Axial Strain in Kovar - Viscoelastic Analysis - Stress Free Tem-

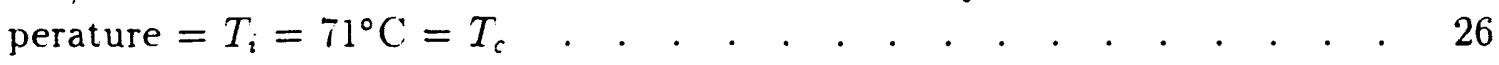

10 828/DEA - Hoop Strain in Kovar - Viscoelastic Analysis - Stress Free Tem-

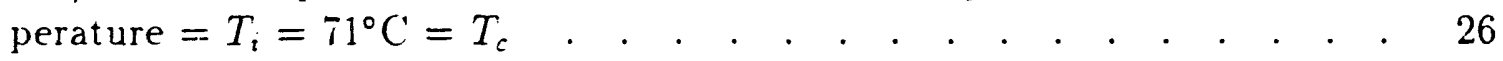

11 828/DEA - Axial Strain in Kovar - Elastic Analysis - Stress Free Temper-

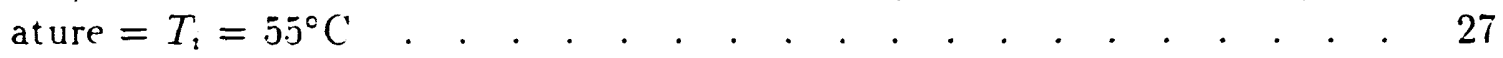

$12828 / D E A$ - Hoop Strain in Kovar - Elastic Analysis - Stress Free Temper-

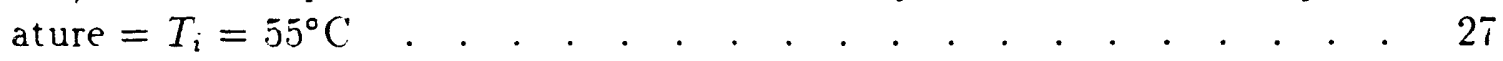

$13828 /$ CTBN/DEA - Axial Strain in Kovar - Elastic Analysis - Stress Free

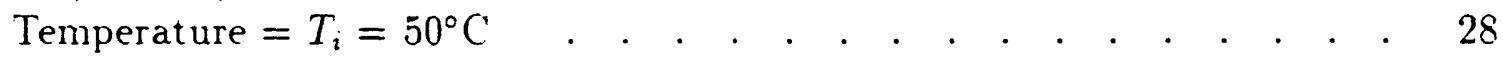

$14828 / C T B N / D E A$ - Hoop Strain in Kovar - Elastic Analysis - Stress Free

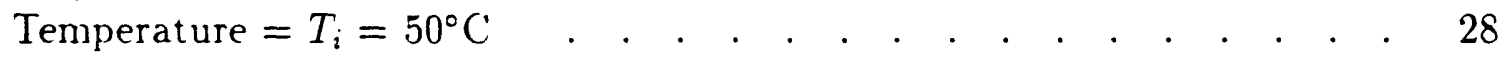

$15828 /$ CTBN/GMB/DEA - Axial Strain in Kovar - Elastic Analysis - Stress

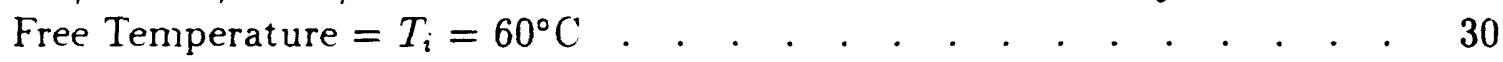

$16828 / C T B N / G M B / D E A$ - Hoop Strain in Kovar - Elastic Analysis - Stress

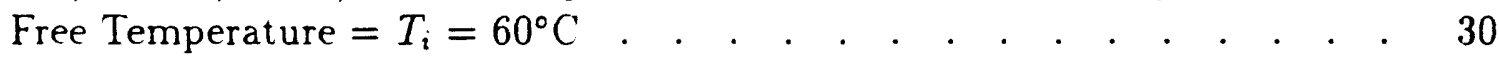

17 SRIR - Axial Strain in Kovar - Elastic Analysis - Stress Free Temperature $=T_{i}=20^{\circ} \mathrm{C}$

18 SRIR - Hoop Strain in hovar - Elastic Analysis - Stress Free Temperature

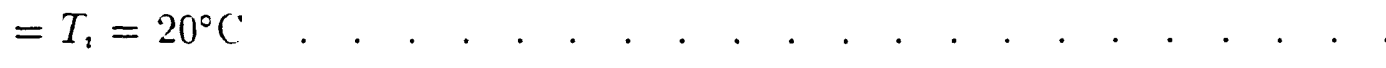

19 Adiprene - Axial Strain in Kovar - Elastic Analysis - Stress Free Tempera-

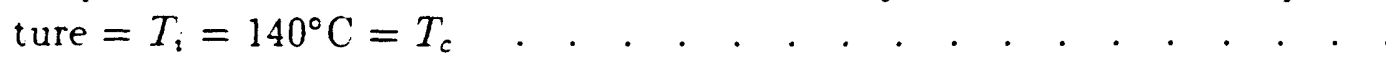

20 Adiprene - Hoop Strain in Kovar - Elastic Analysis - Stress Free Temperature $=T_{i}=140^{\circ} \mathrm{C}=T_{\text {s }}$ 


\section{Introduction}

The design of weapons component assemblies is often critically dependent upon the appropriate use of polymeric encapsulating materials. The encapsulation provides sensitive electrical assemblies with protection against severe shock, vibration, and atmospheric environments. The materials also provide, in many instances, high voltage protection and isolation. Due to substantial differences in thermal expansion between electronic assemblies and the encapsulation materials, however, detrimental stresses and deformations can be developed in the encapsulation process and subsequent thermal excursions. To assist in design and evaluation, accurate predictions of the states of stress and strain in encapsulated assemblies are needed. Finite element computations can yield the desired results provided there are proven material models and accompanying thermomechanical material properties to input into the models.

The states of stress and strain in encapsulated assemblies have been numerically predicted for many years using finite element analyses. These calculations, however, were based on critical assumptions about stress-free conditions in the assembly and material behavior. When a polymeric material cures, complicated chemical reactions occur that produce substantial volume reductions (cure shrinkage) in the encapsulant. The first assumption was that the encapsulation material was stress free and geometrically sound after the cure, i.e., the response during the cure process was neglected. Secondly, to determine the response due to temperature excursions (thermal shrinkage), a stress free temperature $T_{i}$ was assumed. The assumed stress free temperature was either the cure temperature $T_{c}$ or the glass-transition temperature of the encapsulant $T_{g}$. Finally, the stresses in the assembly were normally calculated assuming linear, elastic, temperature dependent material response for the encapsulant; however, in some isolated instances nonlinear (elastic plastic) or viscoelastic material models were employed. It was believed that the stress state predicted with these assumptions were conservative (higher than actual). The predicted responses qualitatively agreed with observed behavior and when the analyses were used to compare various designs, valuable insights were obtained.

More rigorous analyses of encapsulated assemblies must account for both the stresses developed during cure and the thermal and environmental stresses developed after the material cures [1]. At the present time, the development of this rigorous capability is proceeding along parallel paths as schematically illustrated in Figure 1 [2]. Along one path research is focused on developing a methodology to predict curing response in polymeric encapsulants [3]. Before the problem of computing cure-shrinkage stresses in non-isothermally cured encapsulants can be solved. a reaction kinetics and heat transfer model ("thermal model") must first be developed and used to provide both the extent of reaction (conversion) and the temperature as functions of time and position. In the ab- 


\section{CURING RESPONSE}

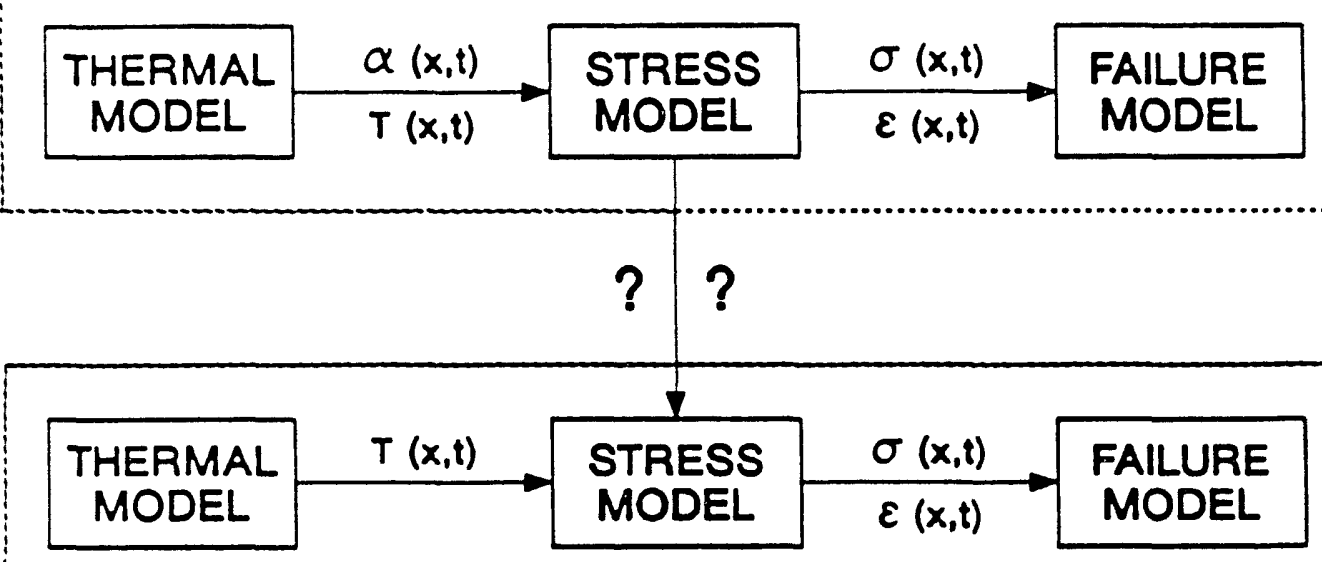

\section{POST-CURING RESPONSE}

Figure 1. Analysis of Encapsulated Assemblies

sence of convection, the thermal model provides the initial conditions for a cure-shrinkage stress model. The development of the stress model involves four tasks: developing a material constitutive model, obtaining material constants, validating the material model, and deriving and implementing finite element solution procedures. Predicted stresses and strains from the cure-shrinkage stress model can then be used to examine possible failure modes during curing. The cure-shrinkage response will, at some point in time, provide the yet to be determined initial conditions for the post-cure analysis.

The second path of the development program involves studies to evaluate the current capability to predict stresses and strains in a fully cured material (post-cure response). Once this capability is established, the post-cure response of an encapsulated assembly due to thermal loading (from an appropriate thermal model) and mechanical loading can be confidently predicted. The predicted stresses and strains can then used to determine possible service failure modes.

This report presents results from combined experimental/analytical research to evalvate the current capability for predicting post-cure stresses and strains for five encapsulating materials. The approach was (1) to perform experiments [4] that made direct in situ measurements of strains that developed in an cmbedded closed cylinder due to cooling from encapsulation temperatures and to subsequent thermal excursions, (2) to perform finite element siress analy'ses of the same experiments using published thermomechanical material properties for the encapsulants, and (3) to compare experimental strains to predicted strains from finite element calculations. The embedded closed cylinder was chosen for two reasons: first. the geometry is representative of many encapsulated assemblies, 
and secondly, the cure shrinkage stresses are minimal. Good agreement would verify that the material constitutive model, the constitutive parameters, and the finite element modeling methodology are valid for calculating stress and strain states in encapsulated assemblies. 


\section{Experimental Procedure}

One goal of the experimental phase of the study was to measure strains developed in encapsulated parts that are actually used in electronic assemblies of interest such as alumina ceramic vacuum tubes. Rather than initially attempt to instrument ceramic tubes, model specimens that readily lend themselves to experimental and analytical evaluation were designed and studied. The model specimens consisted of thin-wall tubes as shown in Figure 2. Kovar tubes were used in order to achieve greater strain sensitivity than could be obtained with ceramic tubes. Kovar was chosen because it has about the same value of coefficient of thermal expansion (CTE) as alumina ceramic. However, a CTE match is not required to validate the models and the tube could have been one of any number of materials.

The Kovar tubes were instrumented with Micro-Measurements CEA-06-125WT-350 biaxial strain gages at the three locations shown in Figure 2: $0^{\circ}, 90^{\circ}$ and $180^{\circ}$ on the inner diameter (ID). The gages were oriented to measure strain in the axial and hoop directions of the thin-wall tubes. The tubes were also instrumented with a Micro-Measurement strain gage temperature sensor and a $\mathrm{T}$-type thermocouple near the $270^{\circ} \mathrm{ID}$ position. Strain gage and thermocouple leads passed through the center of the top end cap. The wire opening was sealed with RTV silicone to prevent the encapsulant from filling the tube interior during the potting step. A threaded bolt through the bottom end cap was used to position the tube in a mold-released aluminum nold as illustrated in Figure 2. The mold-release was required to prevent constraint of the encapsulant by adhesion to sides of the aluminum mold. After the assembly was cured and cooled to room temperature, the aluminum mold was removed.

Three types of experiments were conducted on each tube. Strains and temperatures were monitored (1) during free thermal expansion of a non-encapsulated tube over the temperature range of $-60^{\circ} \mathrm{C}$ to $121^{\circ} \mathrm{C},(2)$ during the potting and cure cycle, and (3) after removal from aluminum mold, during thermal cycling of the encapsulated tube between $-60^{\circ} \mathrm{C}$ and $90^{\circ} \mathrm{C}$. All parts were in thermal equilibrium prior to each strain reading. 

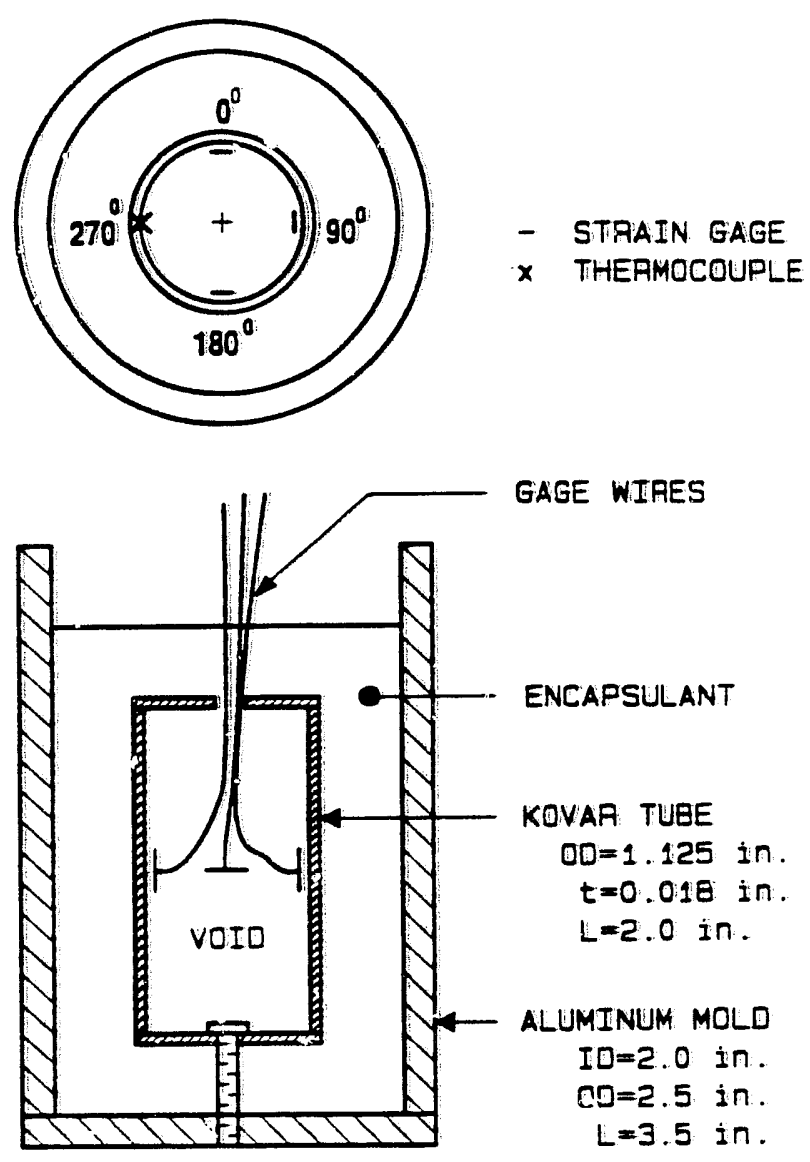

Figure 2. Experimental Configuration 


\section{Finite Element Model}

Two-dimensional finite element analyses were used to predict the strains (and stresses) that developed in the fully cured encapsulated experimental assembly as the temperature of the assembly was cooled from the cure temperature. The two-dimensional geometry and finite element idealization used in this study (Kovar tube $O D=1.125 \mathrm{in}$ ) is shown in Figure 3 . This axisymmetric model takes advantage of a plane of symmetry but does not include the aluminum mold as it was assumed that the encapsulant did not adhere to the mold-released surface of the mold. To perform these calculations one would ideally like to assume the assembly was stress free at the cure temperature of the encapsulant and predict the stresses developed due to both cure shrinkage and thermal shrinkage. However, as stated earlier, the methodology to predict cure shrinkage effects is not complete but is the subject of active research. Therefore, various stress free temperatures were examined in this study. Originally, the stress free temperature was assumed to be the cure temperature $T_{\text {: }}$ of the encapsulant. In subsequent calculations. the assumed stress free temperature was varied to obtain better correlation with experimental results. Thermoelastic calculations were performed using the finite element computer program JAC'2D [5]. and thermo-viscoelastic calculations were obtained with the finite element computer program SANTOS [6].

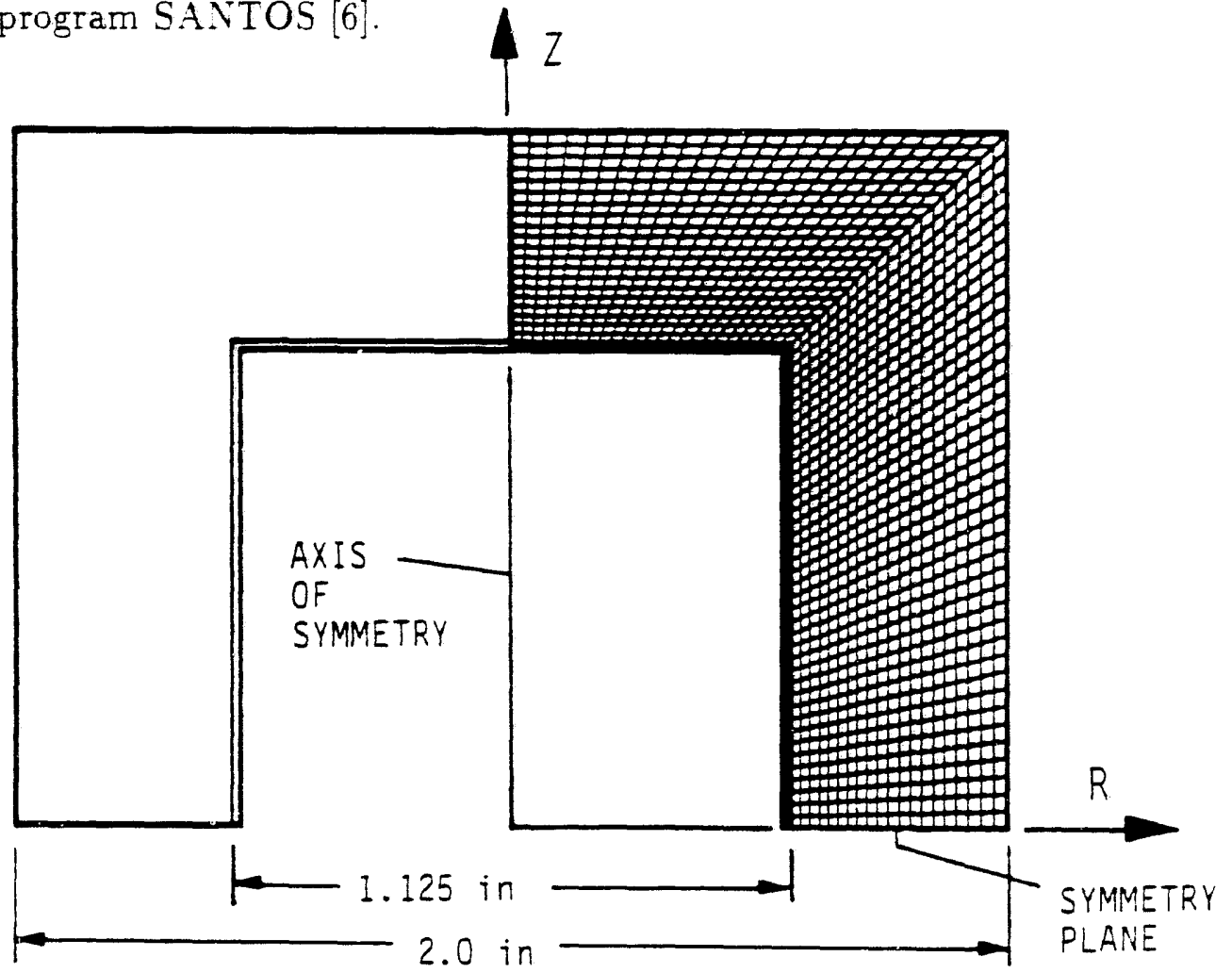

Figure 3. Finite Element Idealization of Experiment 


\section{Encapsulating Materials}

The five encapsulants utilized in this study are listed in Table 1 along with process specification numbers and the cure temperatures used in the experiments. The encapsulants were 1) 828/DEA, an unfilled epoxy system, 2) 828/CTBN/DEA, a rubber toughened epoxy resin. 3) 828 / TBN/GMB/DEA, a rubber toughened epoxy filled with glass microballoons, 4) SRIR, an unfilled semi-rigid epoxy system, and 5) Adiprene L100/BD/TMP. a polyurethane. A wide range of thermal and mechanical properties are represented by these encapsulating materials. The material descriptors above have the following meanings. The 828 designation refers to Shell's Epon 828 epoxy resin which is a formulation of diglycidyl ether of bisphenol A, DGEBA. DEA (diethanolamine) is a liquid curing agent that can be processed to have cure exotherms less than $90^{\circ} \mathrm{C}$. CTBN is a carboxyl-terminated butadiene acrylonitrile rubber used to toughen epoxies. Glass microballoons (GMB) is a filler material that is used to reduce the weight and the coefficient of thermal expansion (CTE) of an encapsulating material without sacrificing other physical properties. Allied Signal's SRIR material is designated as a semi-rigid inspection resin. Because this two-part epoxy system is transparent, it can be used for inspection of encapsulated objects. And finally. Adiprene L-100 is Uniroyal's polyurethane that was cured with BD (1.4-butanediol) and TMP (trimethylolpropane) for 7 hours at $140^{\circ} \mathrm{C}$.

Reference [7] data for the dynamic shear modulus and Tan $\delta$ of the 828/DEA material are plotted as a function of temperature in Figure 4 . The data were measured at a frequency of $2 \mathrm{kHz}$ using a Rheometrics Mechanical Spectrometer RDS- 2 instrument. Of particular interest in this plot is the zone in which the shear modulus changes drastically

Table 1. Materials Studied and Governing Process Specifications

\begin{tabular}{||l|c|c||}
\hline & $\begin{array}{c}\text { Process } \\
\text { Specification }\end{array}$ & $\begin{array}{c}\text { Cure } \\
\text { Temperature } \\
\text { (C) }\end{array}$ \\
\hline $828 / \mathrm{DEA}$ & 9927019 & 71 \\
$828 / \mathrm{CTBN} / \mathrm{DEA}$ & SS331645 (note 1) & 71 \\
828/CTBN/GMB/DEA & 9927092 (note 2) & 93 \\
SRIR & 9927014 & 71 \\
Adiprene L-100/BD/TMP & (note 3) & 140 \\
\hline
\end{tabular}

Note 1:GE Process Specification for 828/CTBN/DEA

Note 2:C'ured at higher temperature than specified in 9927092

Note 3:Processed per instructions on GE Drawings 3021918-200 for MC2993 


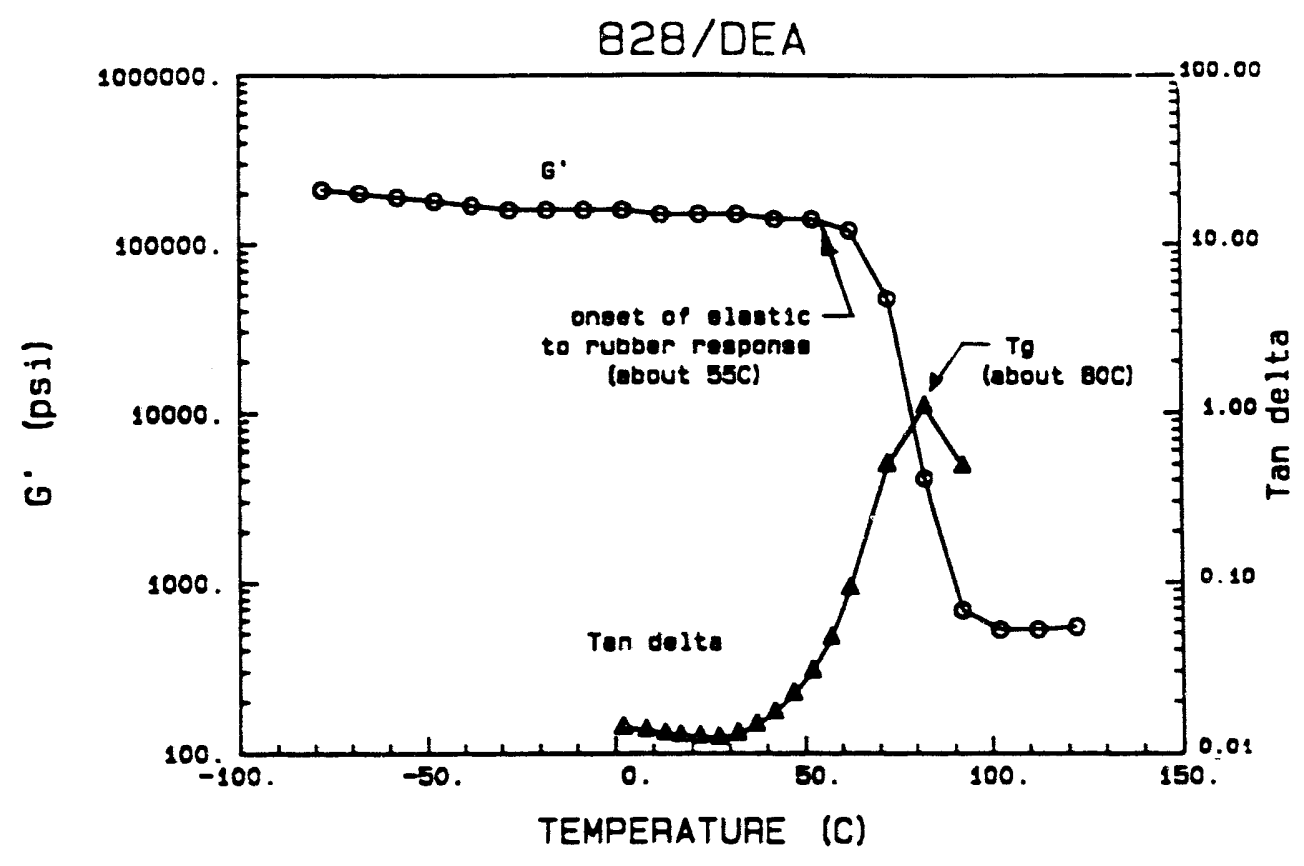

Figure 4. Dynamic Shear Modulus Measured at $2 \mathrm{kHz}$

as the temperature increases. This is a transition zone in which the material changes from a glassy to a rubbery solid. Various types of tests and methods of data interpretation are used to define the glass transition temperature $T_{g}$ from the range of temperatures in the transition zone. Thus, the value assumed for $T_{g}$ is dependent on several factors such as test method, rate of heating. frequency, etc, and is not a unique value. For example, $T_{g}$ can be defined from Figure 4 as the temperature at which the Tan $\delta$ curve peaks.

The cure temperature is normally assumed to be the stress free temperature in an elastic analysis to determine the stresses developed in an encapsulated assembly as the temperature is cooled from the cure temperature. One could, however, define the stress free temperature in other ways, such as the glass transition temperature or the onset of the transition zone from the glassy state to the rubbery state.

Table 2 lists the elastic and thermal expansion properties of the five encapsulants used in the finite element analyses. The elastic properties for 828/DEA, 828/CTBN/DEA, and $828 /$ CTBN/GMB/DEA were obtained from Adolf et al [ 7 ]. The elastic properties for SRIR were taken from the Casting Resins Property Chart [8] and those for Adiprene L100/BD/TMP from Holten [9]. The thermal expansion data for the 828/DEA, 828/CTBN/DEA. 828/CTBN/GMB/DEA, and SRIR were generated by Adolf and Childress [10]. For the Table 2 data. thermal strain is defined as the free thermal expansion due to the coefficient of thermal expansion of the material, with $-55^{\circ} \mathrm{C}$ arbitrarily set as zero strain. In the firite element analysis codes. only differences in thermal strain between two temperatures is considered, not the absolute value. Therefore, any temperature can be selected as the "zero strain" temperature as the strains at other temperatures are 
adjusted appropriately.

The elastic material model and properties presented do not account for time dependent response. However, polymeric materials do exhibit time dependent response. Kirieg and Cessac [11] approximated the response of $828 / \mathrm{DEA}$ as a thermorheologically simple linear viscoelastic material and used a nine term Prony series to define the shear relaxation modulus. In SANTOS, a linear viscoelastic material model implemented by Costin and Stone [12] is used. Using data from Krieg and Cessac, the material constants for 828/DEA were determined. The time-temperature shift function is given by a common WLF equation [13]

$$
\log _{10} \alpha=\frac{C_{1}\left(T-T_{0}\right)}{C_{2}+T_{0}-T}
$$

where

$$
\begin{aligned}
& C_{1}=9.85 \\
& C_{2}=60.0
\end{aligned}
$$

and

$$
T_{0}=50.0^{\circ} \mathrm{C}
$$

The shear modulus is given by:

$$
G(t)=G^{\infty}+\sum_{i=1}^{3} G_{i} \epsilon^{t / \beta_{i}}
$$

where

$$
\begin{aligned}
& G_{1}=50350 p s i \\
& G_{2}=64309 p s i
\end{aligned}
$$

and

$$
G_{3}=532 i \text { ipsi. }
$$

The shear relaxation constants are given by:

$$
\begin{aligned}
& \beta_{1}=6.342 \\
& \beta_{2}=0.41
\end{aligned}
$$

and

$$
\beta_{3}=0.0195 \text {. }
$$

The bulk response is assumed to be elastic with bulk modulus of

$$
K=740000 p s i
$$


Table 2. Temperature-Dependent Material Properties

\begin{tabular}{||l|c|c|c|c||}
\hline & Temperature & Modulus & $\begin{array}{c}\text { Poisson's } \\
\text { Ratio }\end{array}$ & $\begin{array}{c}\text { Thermal } \\
\text { Strain }\end{array}$ \\
\hline (C) & (psi) & & \\
\hline & -55. & 517400. & 0.383 & 0.0 \\
& -30. & 447700. & 0.399 & 0.00113 \\
& 20. & 421500. & 0.405 & 0.00384 \\
& 50. & 395000. & 0.411 & 0.00576 \\
& 60. & 352000. & 0.423 & 0.00650 \\
& 71. & 138400. & 0.470 & 0.00762 \\
& 93. & 2070. & 0.499 & 0.01120 \\
\hline $828 /$ CTBN/DE.A & -55. & 454800. & 0.385 & 0.0 \\
& -30. & 392600. & 0.402 & 0.00160 \\
& 20. & 339700. & 0.415 & 0.00480 \\
& 50. & 282400. & 0.432 & 0.00725 \\
& 60. & 243900. & 0.441 & 0.00808 \\
& 71. & 143500. & 0.464 & 0.00900 \\
& 93. & 21600. & 0.499 & 0.01300 \\
\hline Adiprene & -55. & 491600. & 0.347 & 0.0 \\
& -30. & 438600. & 0.355 & 0.00084 \\
& 20. & 409100. & 0.363 & 0.00275 \\
& 50. & 384100. & 0.372 & 0.00405 \\
& 60. & 363900. & 0.380 & 0.00453 \\
& 71. & 333300. & 0.389 & 0.00522 \\
& 93. & 38660. & 0.487 & 0.00726 \\
\hline SRIR & -55. & 550000. & 0.350 & 0.0 \\
& 0. & 325000. & 0.400 & 0.003315 \\
& 20. & 238200. & 0.450 & 0.004835 \\
& 40. & 15000. & 0.490 & 0.007435 \\
& -55. & 16000. & 0.400 & 0.0 \\
& -50. & 2500. & 0.425 & 0.000972 \\
& -40. & 470. & 0.450 & 0.002915 \\
& -23. & 470. & 0.480 & 0.006160 \\
& 4. & 400. & 0.490 & 0.011540 \\
& & 440. & 0.490 & 0.018070 \\
& & 750. & 0.490 & 0.037900 \\
\hline & & &
\end{tabular}




\section{Results and Discussion}

\section{Validation of Test Procedure}

In the first set of experiments, the apparent strain as a function of temperature was monitored for non-encapsulated Kovar tubes. This apparent strain $\epsilon_{a 1}$ is the sum of 1) the strain $\epsilon_{\text {Kovar }}$ in the Kovar due to its coefficient of thermal expansion (CTE), and 2) the temperature-dependent apparent strain output of the strain gage $\epsilon_{g}$. Experimental values of $\epsilon_{a 1}$ were approximately identical in both the axial and hoop directions for the Kovar tubes. At each test temperature the manufacturer's value of $\epsilon_{g}$ was algebraically substracted from the measured value of $\epsilon_{a 1}$ (average of the three strain gages) to yield measured value of $\epsilon_{\text {Kovar }}$, the free expansion/coniraction strain in the Kovar due to its CTE.

Figure 5 is a plot of $\epsilon_{\text {Kovar }}$ in the axial direction of the Kovar tube as a function of temperature, with the data arbitrarily shown to have zero strain at $20^{\circ} \mathrm{C}$. The solid curve is a quadratic least squares fit $\left(\epsilon_{K^{\circ} \text { ovar }}=-0.007011 \times T^{2}+6.1904 \times T-160.0\right)$ of the experimental data. A secant curve between $-40^{\circ} \mathrm{C}$ and $100^{\circ} \mathrm{C}$ has a slope $\left(5.7 i \times 10^{-6} \mathrm{in} / \mathrm{in} /{ }^{\circ} \mathrm{C}\right)$ that is in excellent agreement with literature values of Kovar CTE. These results indicate that the experimental and data reduction procedures are valid for measuring strains over the temperature range of interest.

\section{Potting and Cure}

If strumented Kovar tubes with Kovar end caps were placed in mold-released aluminum molds and encapsulated. Apparent strains of the encapsulated tubes, $\epsilon_{a 2}$, were monitored during the potting and cure cycle. Thermal strains in the Kovar were obtained by substracting $\epsilon_{g}$ from $\epsilon_{a 2}$. Representative results are shown in Figure 6 for the 828/DEA encapsulant over the 1.125" OD Kovar tube. The maximum oven temperature during cure was $71^{\circ} \mathrm{C}$; however, during the exothermic reaction the resin temperature reached $90^{\circ} \mathrm{C}$.

The solid line in Figure 6 is the free expansion of the Hovar from Figure 5. The strain gages were zeroed at $20^{\circ} \mathrm{C}$ at the start of the experiment. At the cure temperature both the axial and hoop strains in the $828 / \mathrm{DEA}$ encapsulated Kovar tube are equal to the strain in a non-encapsulated Kovar tube. Whenever the encapsulated tube response is the same as the non-encapsulated Kovar tube, there is no mechanically induced strain in the hovar due to differences in CTE of the various materials. During cool-down from $71^{\circ} \mathrm{C}$. the cure temperature, the experimental strains begin to deviate from the Kovar curve. This means that thermal stresses are beginning to develop in the encapsulant and 


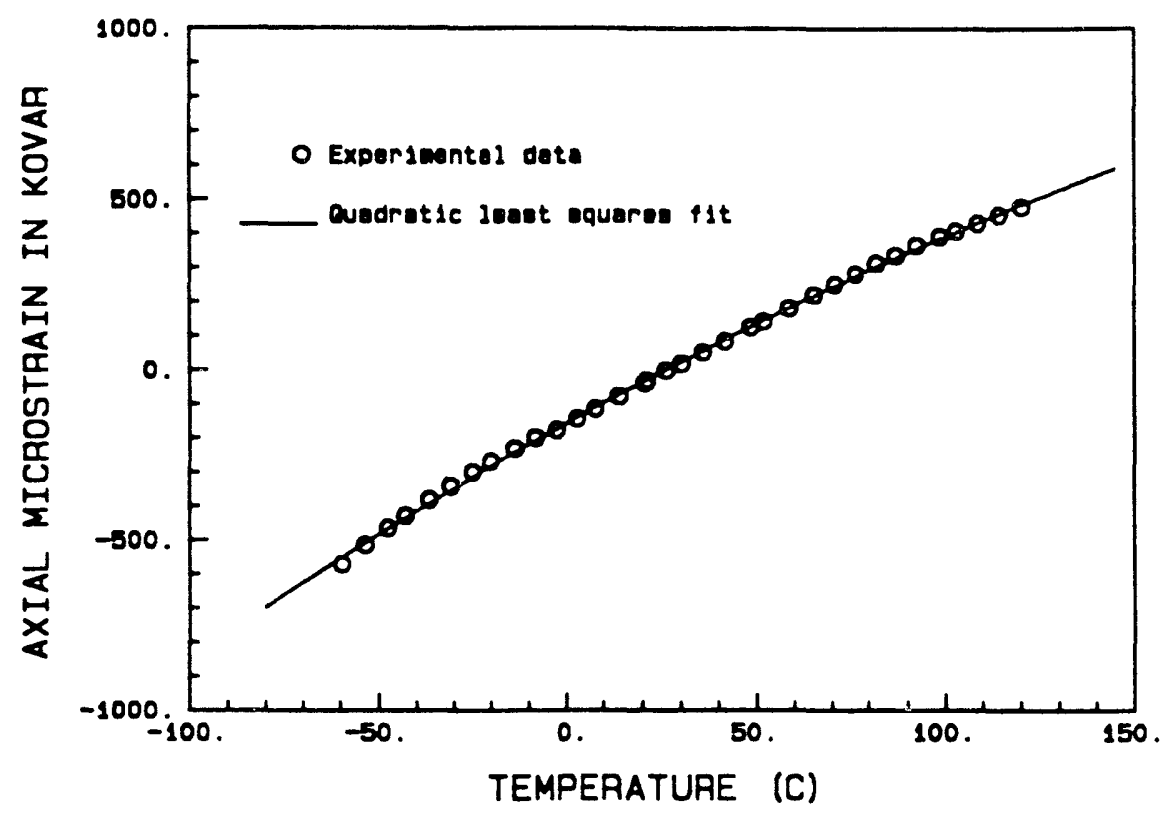

Figure 5. Free Expansion of Non-encapsulated Kovar Tube

in the hovar tube due to the CTE mismatch between the two materials. The temperature at which the strains begin to build appears to be about equal to the temperature for the onset of the glassy-to-rubbery transition region for the potting material. The lowest temperature at which there is no mechanically induced strain in the hovar was an important consideration for setting stress free temperatures in the finite element models of the experiments.

The mechanically induced residual compressive strain in the Kovar at room temperature following the cure cycle is equal to the difference in the curves for non-encapsulated (free expansion) and encapsulated tubes. A comparison of the experimental values of residual strains in the Kovar tubes following potting and cure of the five encapsulants is shown in Table 3 . The fact that there are significant residual strains at room-temperature for DEA cured epoxies and none for the SRIR and Adiprene is a direct result of the differences among glass transition temperatures of the encapsulants.

\section{Thermal Excursions}

\section{Kovar Encapsulated in 828/DEA}

The hovar tube potted in cured $828 / \mathrm{DEA}$ was thermal cycled between $-60^{\circ} \mathrm{C}$ and $90^{\circ} \mathrm{C}$. A pparent strains in the Kovar were corrected for $\epsilon_{g}$, as previously described for the cure cool-down experiments. to yield a combined mechanical plus thermal strain. 


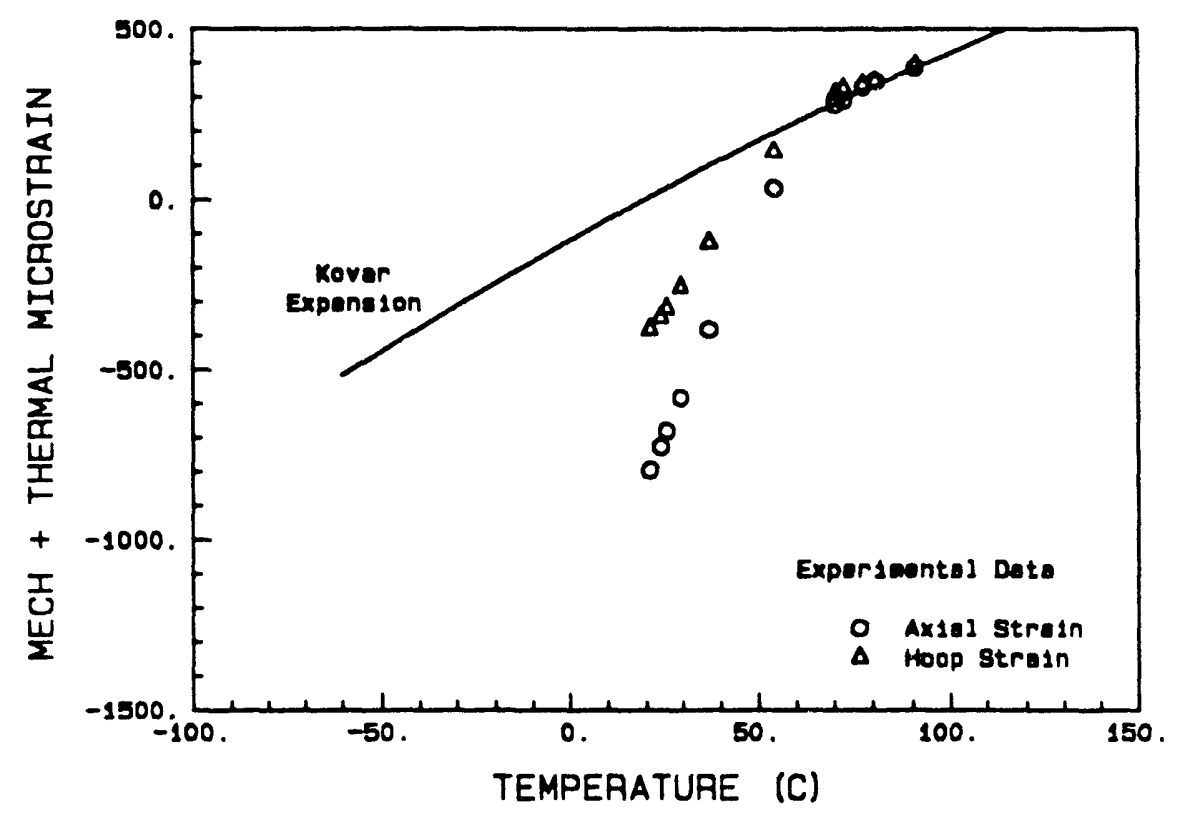

Figure 6. 828/DEA - Potting and Cure Strains

Table 3. Room Temperature Residual Strains in Kovar Tube Following Cure of Encapsulant

\begin{tabular}{||l|c|c||}
\hline & $\begin{array}{c}\text { Residial } \\
\text { Axial } \\
\text { Microstrain }\end{array}$ & $\begin{array}{c}\text { Residual } \\
\text { Hoop } \\
\text { Microstrain }\end{array}$ \\
\hline 828/DEA & -765. & -380. \\
828/CTBN/DEA & -630. & -320. \\
828/CTBN/GMB/DEA & -540. & -230. \\
SRIR & 0. & 0. \\
Adiprene L-100/BD/TMP & 0. & 0. \\
\hline
\end{tabular}




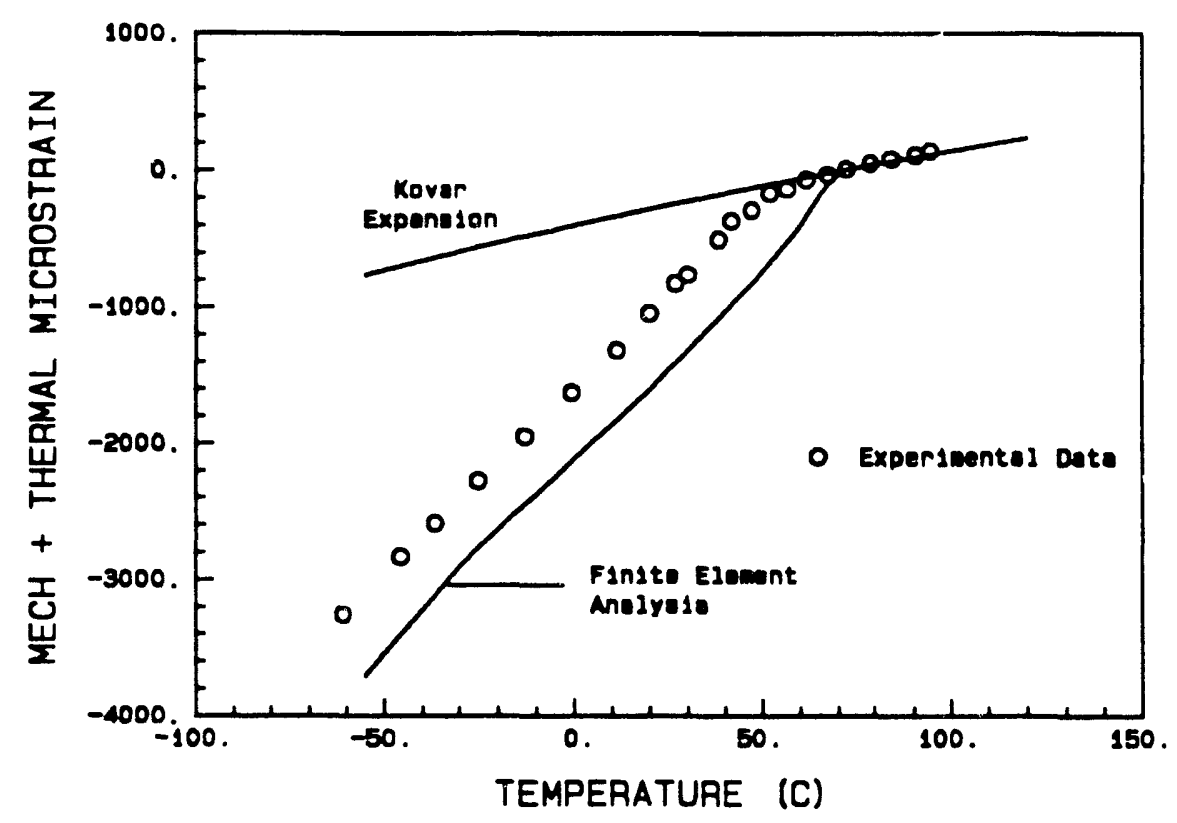

Figure 7. 828/DEA - Axial Strain in Kovar - Elastic Analysis - Stress Free Temperature $=T_{i}=71^{\circ} \mathrm{C}=T_{c}$

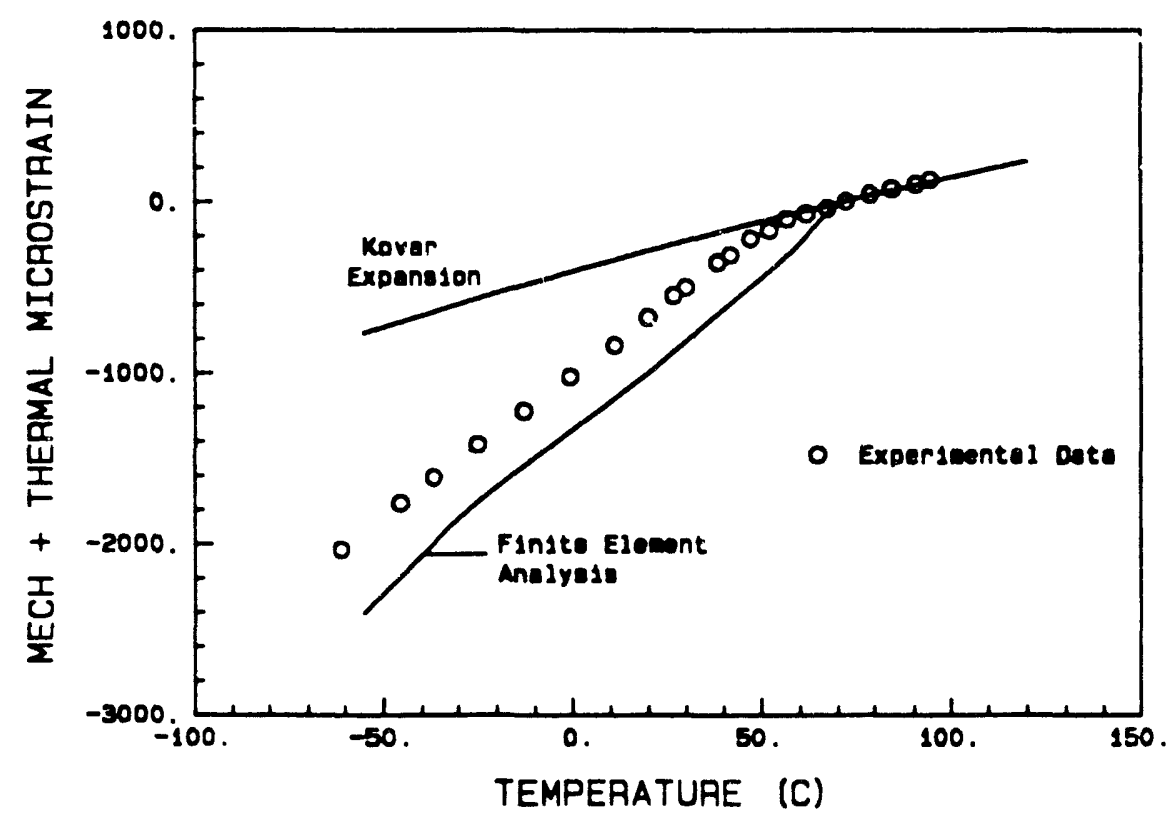

Figure 8. 828/DEA - Hoop Strain in Kovar - Elastic Analysis - Stress Free Temperature $=T_{i}=71^{\circ} \mathrm{C}=T_{c}$ 
Elastic Analysis with $T_{c}$ as Stress Free Temperature - Figures 7 and 8 show the axial and hoop strains, respectively, as functions of temperature, for a Kovar tube potted in $828 / \mathrm{DEA}$. The experimental data (open circles) are set to zero at $71^{\circ} \mathrm{C}$, the cure temperature. Included in these two figures are curves for the free expansion of a non-encapsulated Kovar tube and for finite element analyses of the experimental assembly The material model incorporated in the analysis is a linear, elastic, temperaturedependent model using the properties listed in Table 2. The stress free temperature is assumed to equal the cure temperature of the $828 / \mathrm{DEA}$. The slopes of computed and measured strain-temperature curves are in reasonable agreement. However, at $-50^{\circ} \mathrm{C}$ the finite element analysis over estimates the compressive mechanical strains by about $25 \%$ in the axial direction and $40 \%$ in the hoop direction.

Viscoelastic Analysis with $T_{c}$ as Stress Free Temperature - Strains computed with the previously described viscoelastic material model for $828 / \mathrm{DEA}$ are shown in Figures 9 and 10. These figures also include the experimental data and the free expansion strains of Kovar. Calculated viscoelastic responses are plotted for two rates of cooling. The assembly was first assumed to be uniformly cooled from the cure temperature to the cold temperature extreme in two hours and, secondly, in four hours. The calculated results are not significantly affected by the two rates of cooling assumed in these calculations. Near the stress free temperature, the viscoelastic calculations produce a nonlinear response that is similar to the nonlinear response observed in the experiment. The calculated hovar strains are in excellent agreement with experimental data with a slightly better correlation for the hoop strains than for the axial strains.

Elastic Analysis with Onset of Glassy-to-Rubbery Transition Region as Stress Free Temperature - It is clear from Figures 7-10 that the Kovar tube encapsulated in $828 / \mathrm{DEA}$ begins to pick up mechanically induced strain when the temperature is lowered to about $55^{\circ} \mathrm{C}$. In the shear modulus vs. temperature material tests by Adolf $[i]$, the temperature at which the $828 / \mathrm{DEA}$ begins to transition from glassy to rubbery response also corresponds to about $55^{\circ} \mathrm{C}$ as shown in Figure 4 . Finite element analyses with the linear, elastic, temperature-dependent material model for the $828 / \mathrm{DEA}$ potting material were performed for the condition of a $55^{\circ} \mathrm{C}$ stress free temperature. The results are shown in Figures 11 and 12. Excellent agreement is observed between the computed strains and the experimentally measured strains over the entire temperat ure range.

Summary - 828/DEA - In summary, three material models were used in finite element analyses to calculate strains in the 828/DEA encapsulated Kovar tube during thermal excursions. The results show that an elastic analysis yields excellent agreement with experimental data when the stress-free temperature is set equal to the temperature at which the Kovar tube begins to pick up mechanically induced strains in the tube experiments. This temperature corresponds to the onset of the glassy-to-rubbery transition temperature as indicated by dynamic shear modulus vs. temperature data. A viscoelastic 


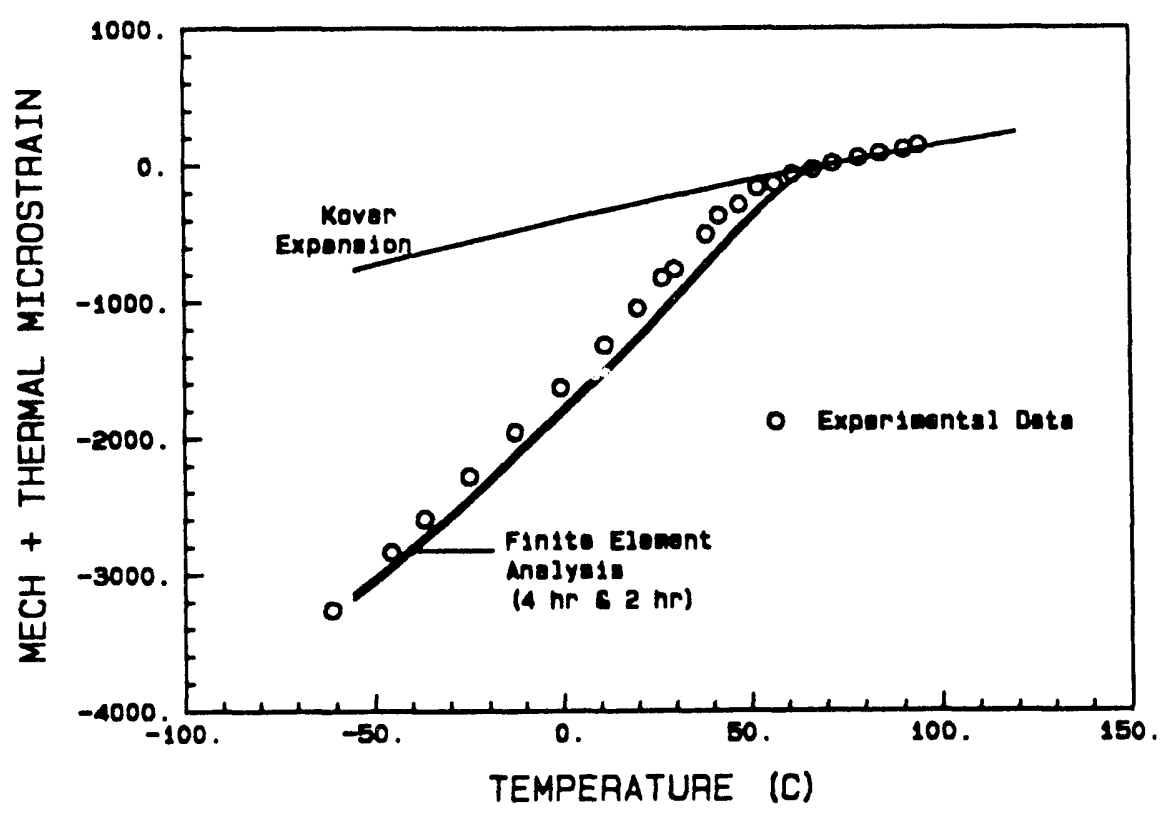

Figure 9. 828/DEA - Axial Strain in Kovar - Viscoelastic Analysis - Stress Free Temperature $=T_{i}=71^{\circ} \mathrm{C}=T_{\mathrm{c}}$

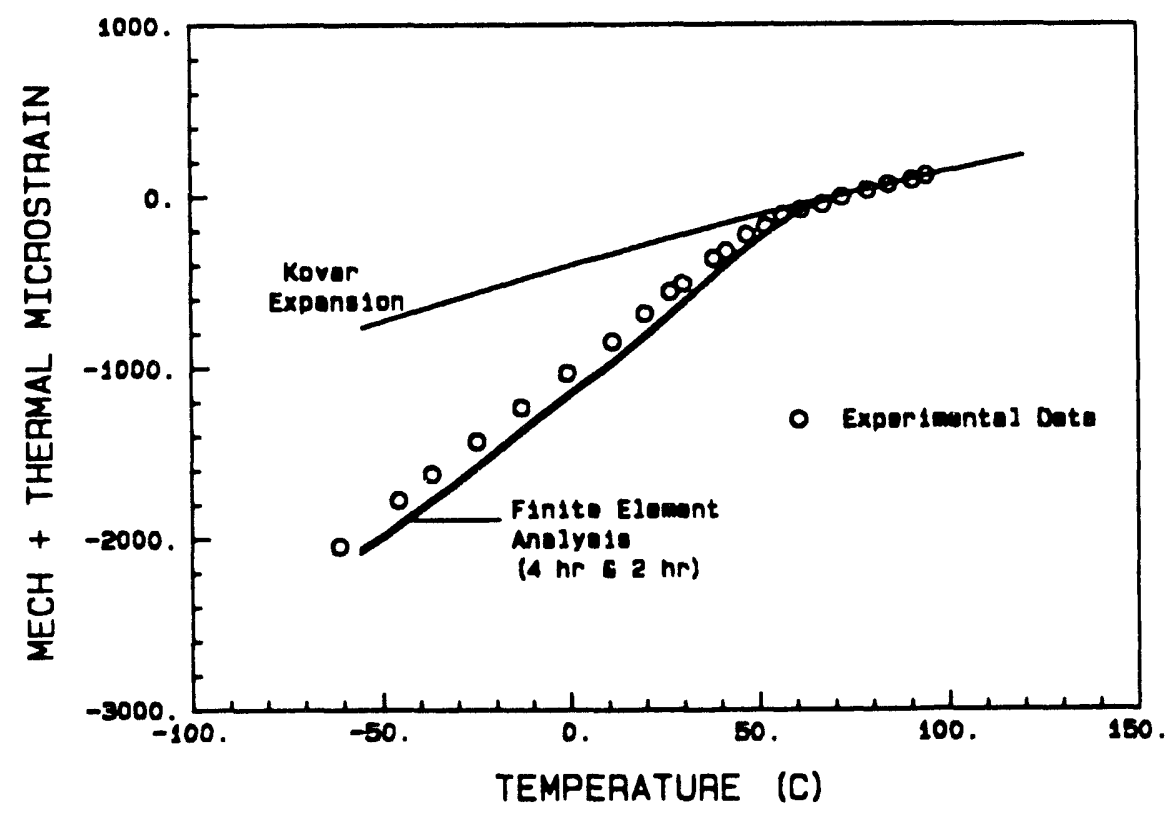

Figure 10. 828/DEA - Hoop Strain in Kovar - Viscoelastic Analysis - Stress Free Temperature $=T_{i}=71^{\circ} \mathrm{C}=T_{c}$ 


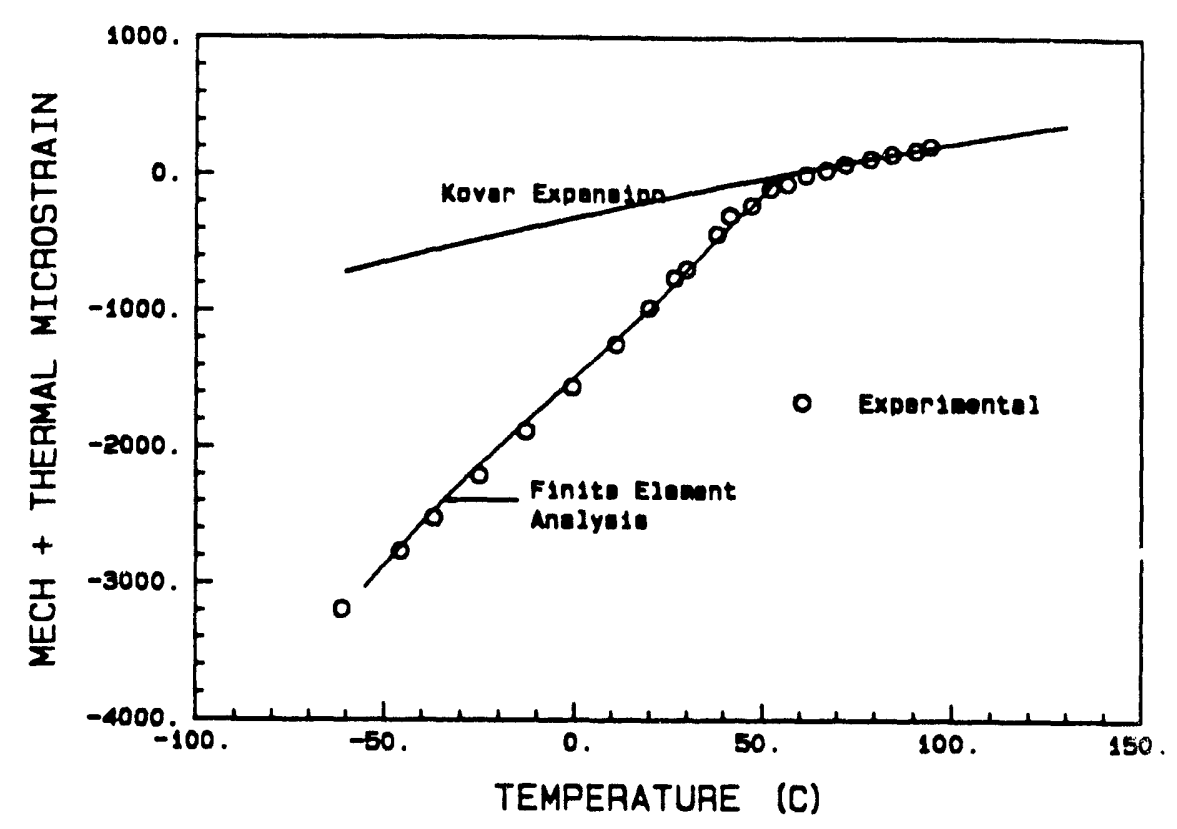

Figure 11. 828/DEA - Axial Strain in Kovar - Elastic Analysis - Stress Free Temperature $=T_{i}=55^{\circ} \mathrm{C}$

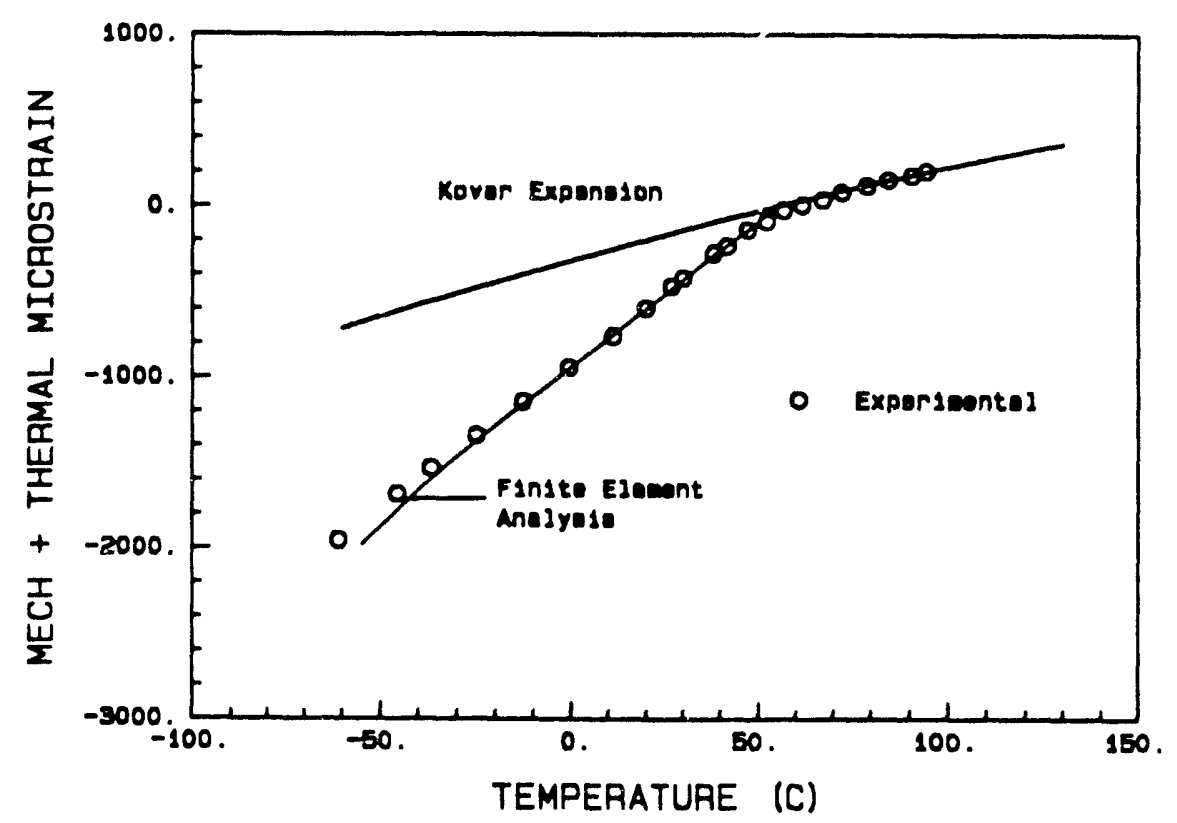

Figure 12. 828/DEA - Hoop Strain in Kovar - Elastic Analysis - Stress Free Temperature $=T_{i}=55^{\circ} \mathrm{C}$ 


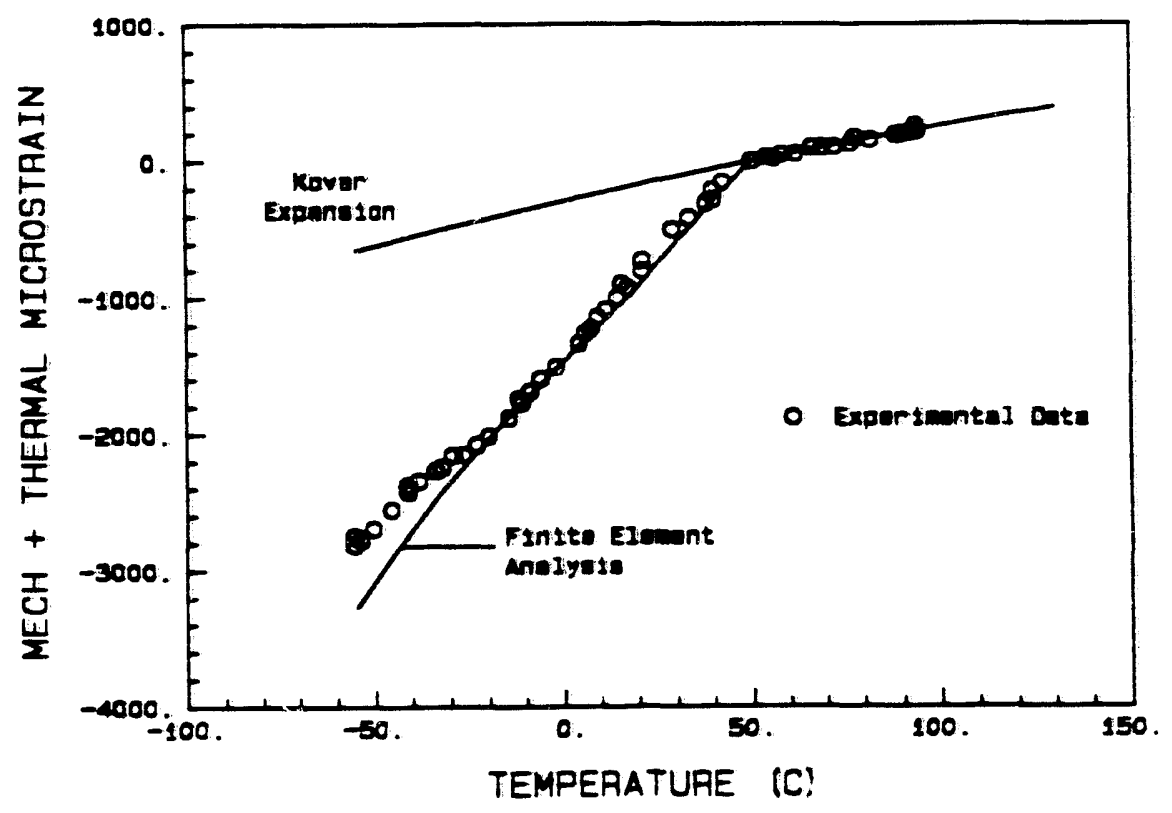

Figure 13. 828/CTBN/DEA - Axial Strain in Kovar - Elastic Analysis - Stress Free Temperature $=T_{i}=50^{\circ} \mathrm{C}$

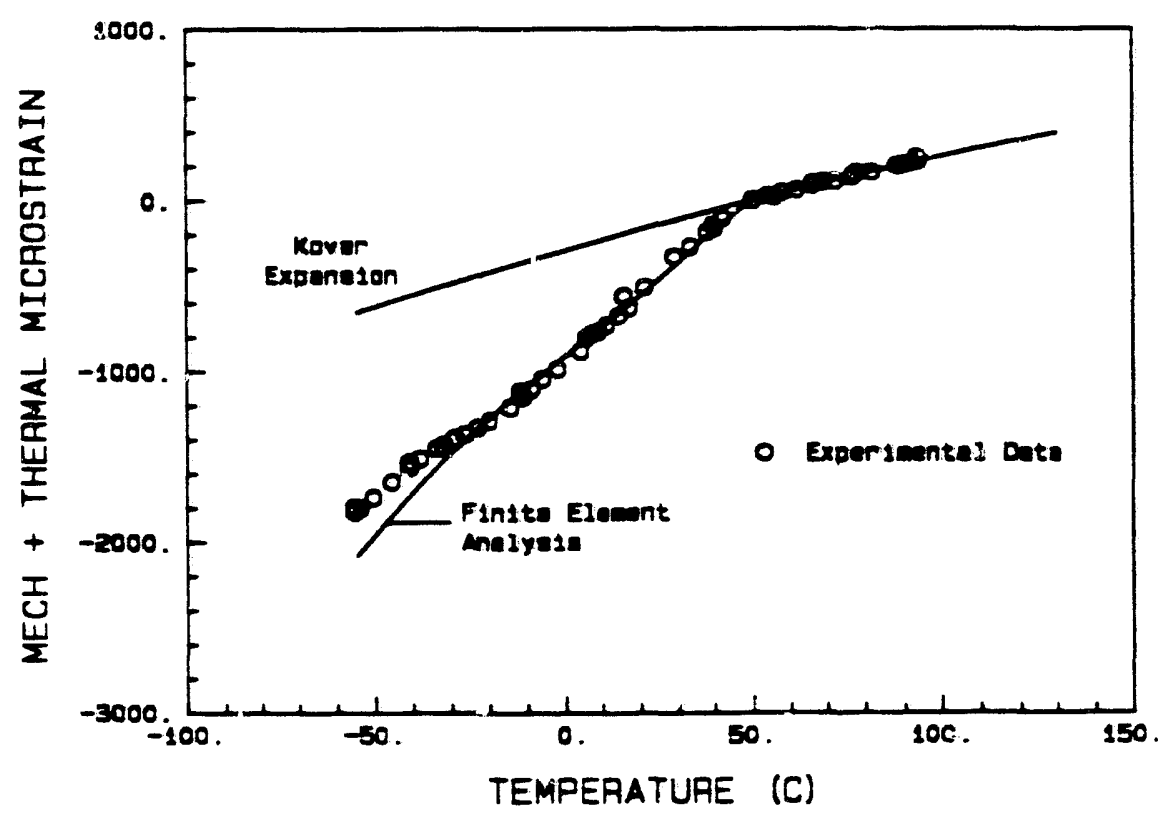

Figure 14. 828/CTB:i/DEA - Hoop Strain in Kovar - Elastic Analysis - Stress Free Temperature $=T_{i}=50^{\circ} \mathrm{C}$ 
model with the cure temperature, $T_{c}$, as the stress free temperature also vielded excellent agreement with experiment. In addition this model reproduced the nonlinear behavior near the stress free temperature. Because viscoelastic properties are not presently available for the other four encapsulants, only elastic material properties with a stress free temperature taken from the experimental data were used in finite element analyses of Kovar tubes potted in the other four encapsulants.

\section{Kovar Encapsulated in 828/CTBN/DEA}

Comparisons of elastic analyses with experiment are shown in Figures 13 and 14 for the $828 / \mathrm{CTBN} / \mathrm{DEA}$ potting. Based on the experimental data, the stress free temperature is taken to be $50^{\circ} \mathrm{C}$. The finite element predictions are in good agreement with experimental data at all temperatures down to $-30^{\circ} \mathrm{C}$, below which the analysis overestimates the strain. The shape of the experimental curve at the low temperatures suggest that there may be a secondary glass transition in $828 / \mathrm{CTBN} / \mathrm{DEA}$ near $-30^{\circ} \mathrm{C}$.

\section{Kovar Encapsulated in 828/CTBN/GMB/DEA}

Fig'ures 15 and 16 show the experimental and analytical results for hovar potted in $828 / \mathrm{CTBN} / \mathrm{GMB} / \mathrm{DEA}$ assuming a stress free temperature of $60^{\circ} \mathrm{C}$ for the finite element computations. The agreement is not quite as good as for the two previous encapsulants. The slope of the analytical curve is greater than the experimental curve. Thus, for the elastic analysis with a $60^{\circ} \mathrm{C}$ stress free temperature, the finite element analysis underestimates the Kovar strain at temperatures above $20^{\circ} \mathrm{C}$ and overestimates them below that temperature.

\section{Kovar Encapsulated in SRIR}

As noted in the material properties section, the most recent documented data for SRIR is from a 20 year old chart which listed elastic data at four temperatures. An elastic analysis based on chese properties and a stress free temperature of $20^{\circ} \mathrm{C}$ are in good agreement with the experimental data over the entire temperature range as can be seen in igures 17 and 18. The slopes of the computed curves are greater than the experimental curves. Therefore, at the low temperatures the finite element results are conservative, i.e., they overestimate the compressive stresses in the Kovar. Note again that there are no residual strains in the encapsulated tube at room temperature which is near the SRIR glass transition temperature.

\section{Kovar Encapsulated in Adiprene L-100/BD/TMP}

The comparison of the experimentally measured and computed strains for the urethane elastomer which was cured at $140^{\circ} \mathrm{C}$ and thermal cycled down to $-80^{\circ} \mathrm{C}$ are shown in Figures 19 and 20. For the finite element calculations of this experiment, elastic, 


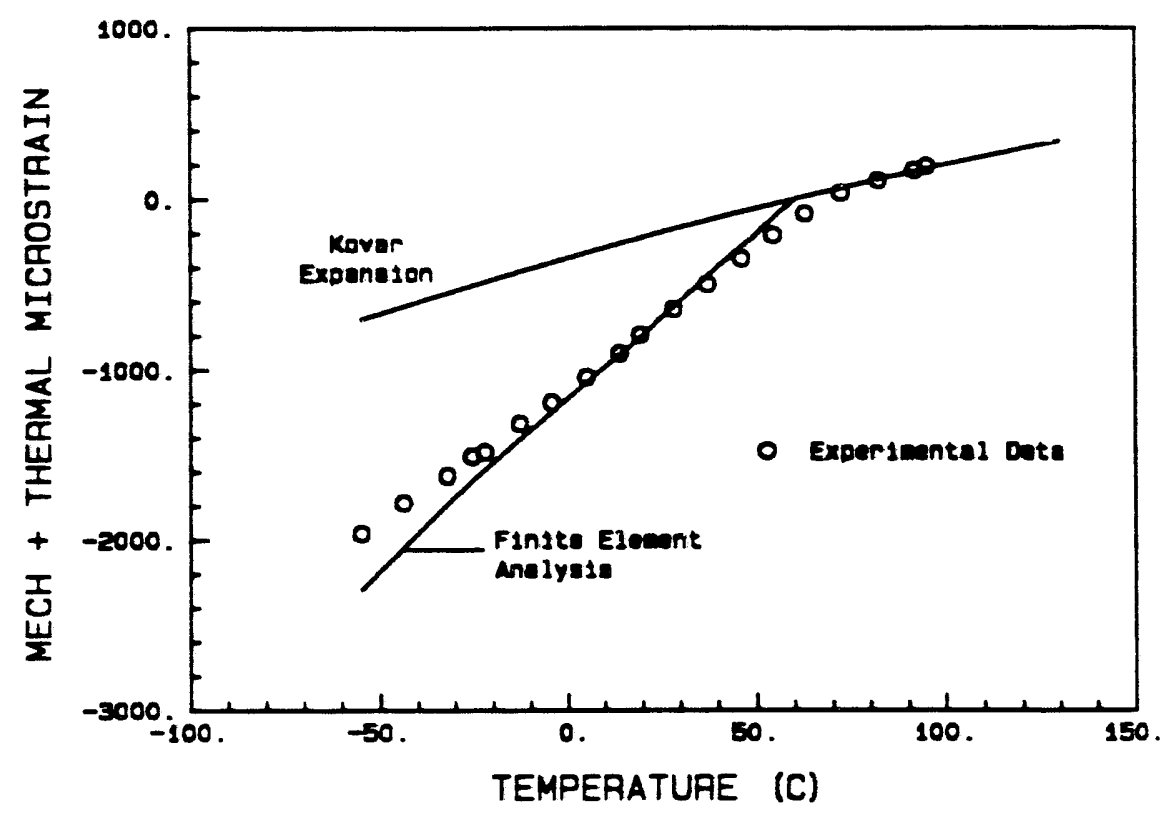

Figure 15. 828/CTBN/GMB/DEA - Axial Strain in hovar - Elastic Analysis - Stress Free Temperature $=T_{i}=60^{\circ} \mathrm{C}$

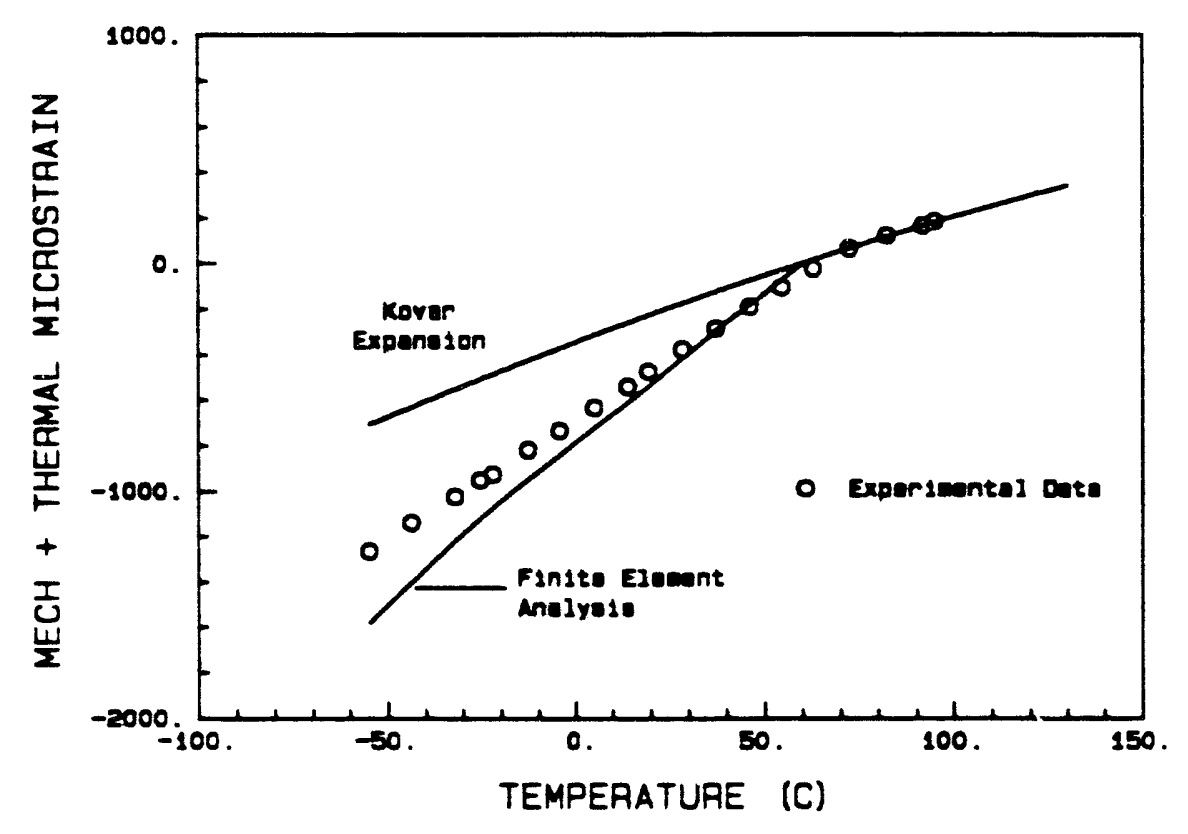

Figure 16. 828/CTBN/GMB/DEA - Hoop Strain in hovar - Elastic Analysis - Stress Free Temperature $=T_{i}=60^{\circ} \mathrm{C}$ 


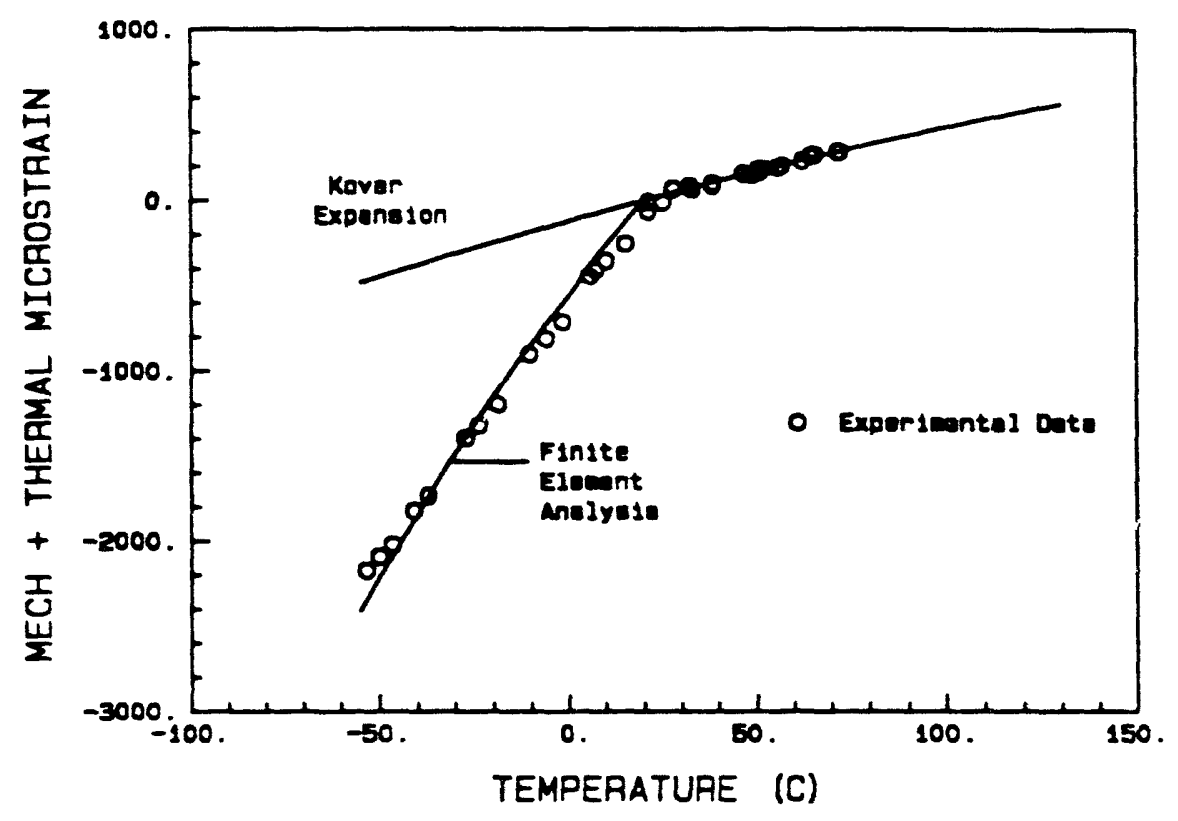

Figure 17. SRIR - Axial Strain in hovar - Elastic Analysis - Stress Free Temperature $=T_{\imath}=20^{\circ} \mathrm{C}$

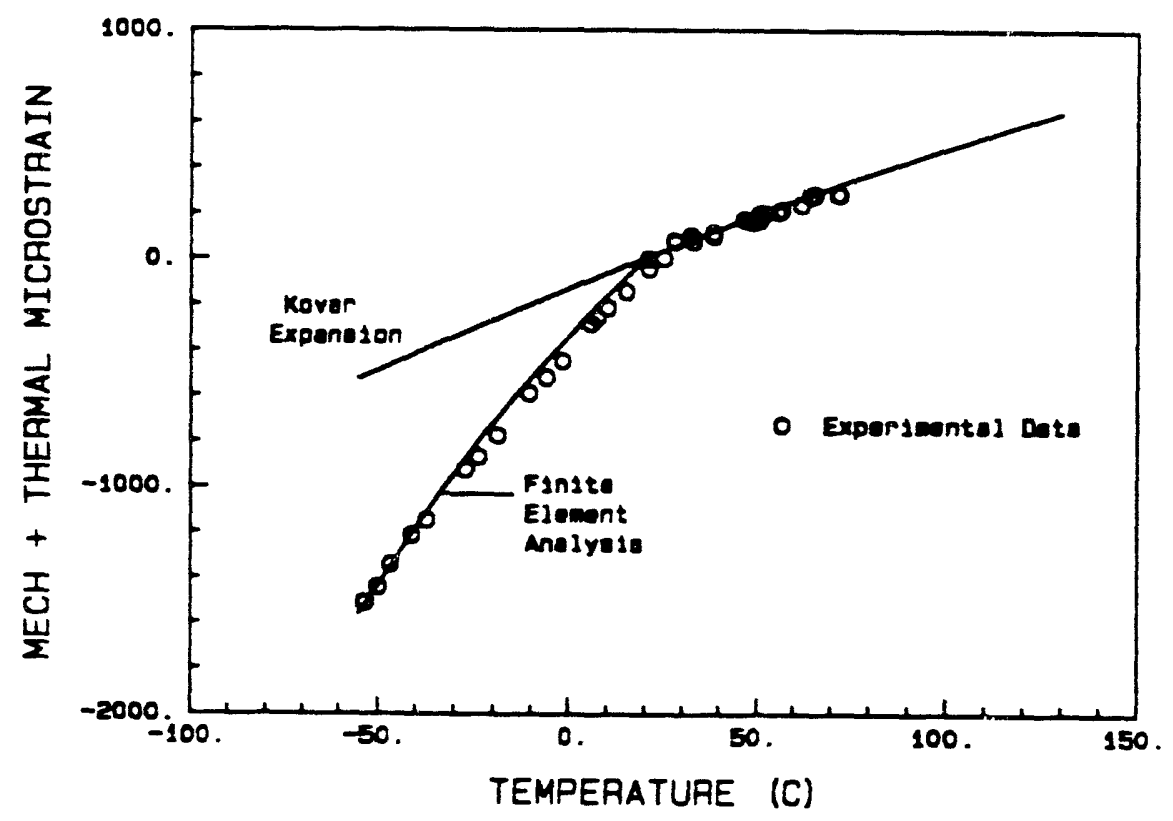

Figure 18. SRIR - Hoop Strain in hovar - Elastic Analysis - Stress Free Temperature $=T_{i}=20^{\circ} \mathrm{C}$ 


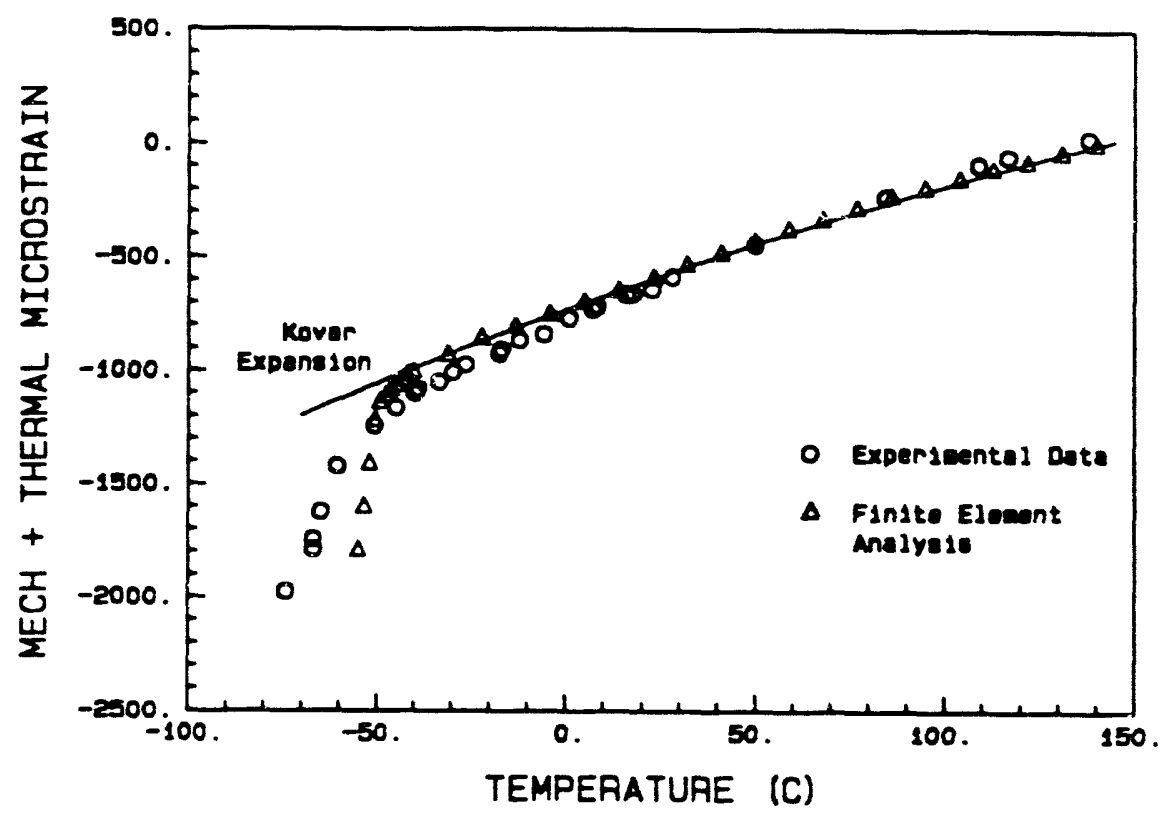

Figure 19. Adiprene - Axial Strain in Kovar - Elastic Analysis - Stress Free Temperature $=T_{2}=140^{\circ} \mathrm{C}=T_{c}$

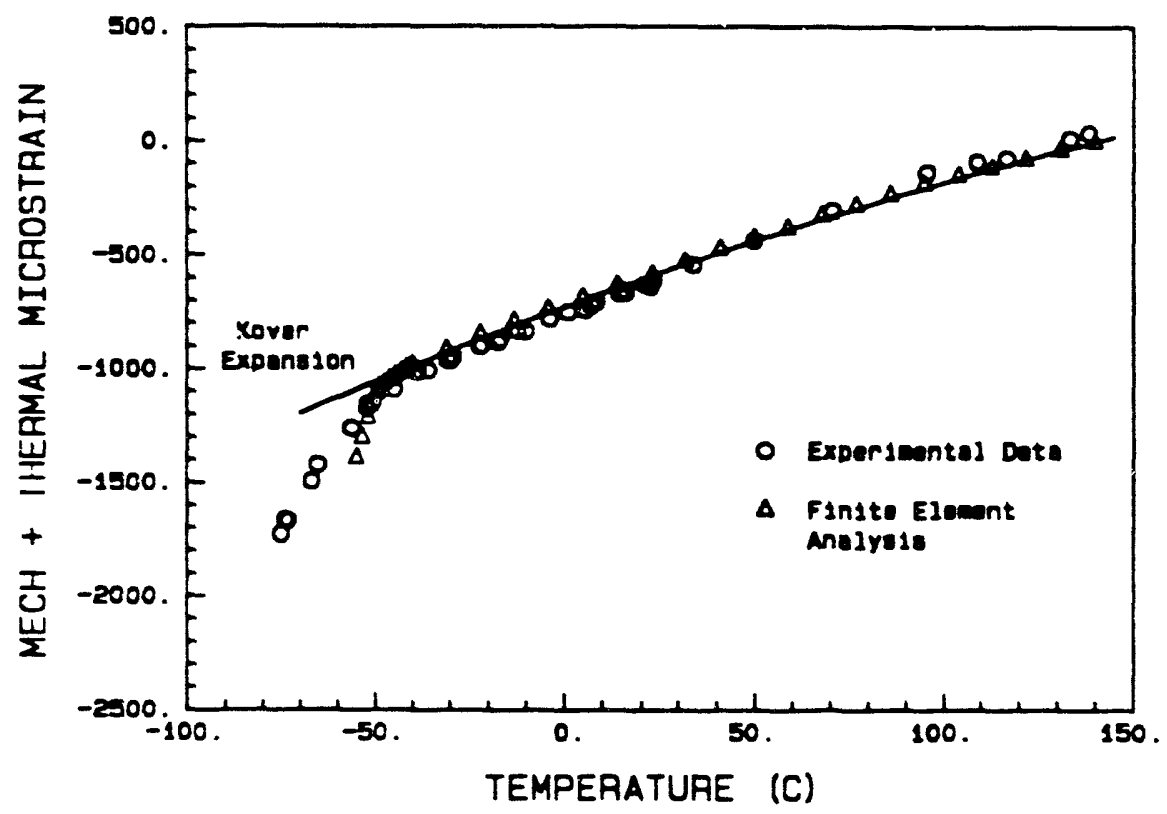

Figure 20. Adiprene - Hoop Strain in hovar - Elastic Analysis - Stress Free Temperature $=T_{i}=140^{\circ} \mathrm{C}=T_{c}$ 
temperature-dependent properties were used while setting zero strain in the hovar at the $140^{\circ} \mathrm{C}$ cure temperature. The computed strains agree with the free expansion strains of the hovar down to a temperature of about $-40^{\circ} \mathrm{C}$, which is near the glass transition temperature of the material. Note that the experimental data deviate slightly from the hovar free expansion curves, possibly due to experimental error. Once mechanical strains begin to build in the $-40^{\circ} \mathrm{C}$ to $-50^{\circ} \mathrm{C}$ range, the slopes of the experimental and analytical curves are significantly different with the computed strain overestimating those measured in the hovar. However, at $-55^{\circ} \mathrm{C}$ which is the low end of most temperature requirements, very little mechanical strain develops in the Kovar encapsulated in the urethane elastomer.

\section{Comments}

It is important to note that all experiments discussed in this paper were for hovar tubes over-potted with encapsulants. The outside surfaces were not constrained during cure and thermal cycling because the aluminum mold was mold-released. For this condition. the volumetric shrinkage that occurs in polymers during gelation and cure does not contribute to the generation of mechanical strains in the Kovar. Volumetric shrinkage can be an important parameter when the resin is constrained during gelation and cure. An example of this condition is a thin tube filled with an encapsulant. When there is good adherence between the hovar and the encapsulant, significant stresses and strains can develop in the tube and encapsulant during gelation and cure due primarily to volume shrinkage and the development of mechanical stiffness (shear modulus) during the gelation process. Experimental and modeling studies of thin tubes filled with 828/DEA have been reported elsewhere[3]. 


\section{Summary}

1. An experimental technique to measure in situ strains during potting. curing and thermal cycling of encapsulated assemblies has been developed and demonstrated.

2. The accuracy and validity of the experimental procedure were demonstrated by measuring the coefficient of thermal expansion of thin Kovar tubes. These results were in excellent agreement with literature values.

3. Kovar tubes were potted in five encapsulating resins (828/DEA, 828/CTBN/DEA. 828/CTBN/GMB/DEA, SRIR, and Adiprene L-100/BD/TMP) and monitored for strains during potting, cure, and thermal excursions. The epoxies with DEA produced residual compressive axial strains of $765 \mu$ strain in the Kovar at room temperature. This strain results because of the differential in coefficient of thermal expansion between the Kovar and the encapsulants and because the glass transition temperatures $T_{g}$ of these potting materials are above room temperature. On the other hand, the SRIR and Adiprene do not produce room temperature residual strains in the Kovar because the glass transition temperatures are approximately equal to or below room temperature $\left(25^{\circ} \mathrm{C}\right.$ and $-45^{\circ} \mathrm{C}$, respectively).

4. Elastic and viscoelastic material properties were used in finite element models of the thermal excursion experiments of thin Kovar tubes encapsulated in 828/DEA. The elastic analysis yielded conservative results (predicted strains higher than measured strains) when the stress-free temperature was set equal to the cure temperature.

The elastic analysis yielded excellent agreement with experimental data over the entire temperature range prorided the stress-free temperature was set equal to the temperature at which the Kovar tube began to pick up mechanically induced strains in the tube experiments. This temperature can be identified in material properties data, such as dynamic shear modulus v's temperature data by picking the temperature for the onset of the transition region from glassy response to the rubbery state. Since the dynamic shear modulus vs temperature curve is dependent on many factors such as test method, frequency, and rate of heating. it is difficult to obtain a unique value for the stressfree temperature. In these calculations the stress-free temperature in effect becomes a required material property value which must be obtained for an accurate analysis.

A viscoelastic analysis with $T_{g}$ as the stress free temperature also yielded excellent agreement with experiment. In the viscoelastic analysis, however, it was not necessary to choose an "appropriate" stress-free temperature. The viscoelastic analysis reproduced the nonlinear behavior experimentally observed near the stress free temperature.

The experiments with 828 /DEA suggest that it is not absolutely necessary to include 
the viscoelastic behavior of epoxy potting materials to capture the principle features of the experimental results and to calculate strains (and stresses) in encapsulated components provided that the apparent stress-free temperature can be determined. However, a viscoelastic model is required to predict the nonlinear response that occurs near the stress free temperature or if stress-free temperature is unknown. Additionally, time dependent response such as the effect of long time storage can only be predicted with a viscoelastic model.

5. Viscoelastic properties were not available for the other four encapsulants. Therefore, finite element analyses of the experiments with these potting materials used elastic, temperature-dependent material properties along with the experimentally inferred stress-free temperature. In general there was good agreement between experimental and predicted strains in the Kovar over the entire temperature range. When the comparisons were not in exact agreement, the finite element results tended to be conservative, i.e., the strains in the hovar were over estimated.

6. In the experiments described in this paper, the encapsulants were not constrained by the aluminum mold. Therefore, isothermal volume shrinkage of the resin during the gel process did not contribute to the build-up of Kovar strains. For hypothetical cases where potting materia's are constrained. volume shrinkage can be important and the set of material properties presented and verified in this study may not be sufficient for an accurate finite element analysis.

i. The results of this study suggest that the thermomechanical, elastic properties listed in Table 2 accurately characterize the five encapsulants provided that the apparent stress-free temperature can be determined. 


\section{References}

1. S. N. Burchett, 1521,"Encapsulant Materials Support - Stress Analysis Needs," memo to W. R. Leuenberger, 7484, Sandia National Laboratories, Albuquerque NM. March 23, 1988.

2. R. S. Chambers, R. R. Lagasse, and T. R. Guess, "A Cure Shrinkage Model for Analyzing the Stresses and Strains in Encapsulated Assemblies During Curing," SA.ND91-1829A, Sandia National Laboratories, Albuquerque, New Mexico, Submitted for presentation at the ASME/JSME Joint Conference on Electronic Packaging. April 9-12, 1992, San Jose, CA.

3. R. S. Chambers, 1523, T. R. Guess, 7472, and R. R. Lagasse, 1813, "Progress in the Development and Validation of a Material Model for Predicting Cure Shrinkage Effects in Thermoset Encapsulants," memo to Distribution, Sandia National Laboratories. Albuquerque NM, March 30, 1990.

4. T. R. Guess. 74i2. "Proposed Experimental Studies Related to Neutron Generator Applications." memo to J. A. Sayre, 7472, Sandia National Laboratories, Albuquerque NM. January 12, 1988.

5. J. H. Biffle. "JAC' - A Two-Dimensional Finite Element Computer Program for the Non-Linear Quasistatic Response of Solids with the Conjugate Gradient Method," SA.ND81-0998. Sandia National Laboratories, Albuquerque NM. April 1984.

6. C'. M. Stone. "SANTOS A Two-Dimensional Finite Element Program for the Quasistatic, Large Deformation, Inelastic Response of Solids," SAND90-0543, Sandia National Laboratories, Albuquerque NM, in preparation.

T. D. Adolf, C. Childress, and D. Hannum, "Bulk and Shear Moduli of Epoxy' Encapsulants." SAND89-0748, Sandia National Laboratories, Albuquerque NM, August 1989.

8. A. J. Quant and C. M. Hatcher, "Casting Resins Properties Chart," Sandia National Laboratories. Albuquerque NM, February, 1964.

9. D. I. Holton, "Evaluation of Alternate Cure Schedule for Adiprene L-100 Elastomer," General Electric Neutron Devices Department Technical Memorandum, No. 527. March 13.1970.

10. D. Adolf and C. Childress, "Coefficients of Thermal Expansion of Common Encapsulants," SAND88-07TT, Sandia National Laboratories, Albuquerque NM, July. 1988. 
11. R. D. Krieg, 1541, and G. L. Cessac, 2316, "Viscoelastic Properties of Epon 828/DEA."memo to Distribution, Sandia National Laboratories, Albuquerque NM, March 29, 1974.

12. L. S. Costin and C. M. Stone, "A Linear Viscoelastic Material Model for SANCHO," SAND85-1836, Sandia National Laboratories, Albuquerque NM, October, 1985.

13. M. L. Williams, R. F. Landel, and J. D. Ferry, "The Temperature Dependence of Relaxation Mechanisms in Amorphous Polymers and other Glass-Forming Liquids," J. Am. Chem. Soc. 77, 3701-3707, 1955. 


\section{Acknowledgments}

G. D. Jones, 1812, and M. E. Stavig, 2472, were responsible for instrumenting kovar tubes with strain gages and thermocouples. They also participated in some of the thermal cycling tests. H. L. Anderson, Jr., 2472, encapsulated all units except those with the polyurethane elastomer which was potted by R. L. Myers, 2472. R. S. Chambers, 1514, and D. Adolf, 1813, reviewed and commented on the original manuscript. 


\section{Unlimited Release}

Allied-Signal Aerospace Co. (3)

P. O. Box 419159

Kansas City, Mo 64141

Attn:

Jim Mahoney

Marc Shrank

R S Sanders

General Electric Company (7)

P. O. Box 2908

Largo, FL 34292

Attn:

E. L. Manson,D/100

R. J. Antepenko,D/031

T. Gillespie, $\mathrm{D} / 048$

M. A. Merkel,D/049

W. E. Swartz,Jr.,D/032

B. J. Wells,D/033

1153 J. E. Martin

1510 J. C. Cummings

1514 H. S. Morgan

1514 V. L. Bergmann

1514 S. ‥ Burchett (10)

1514 R. S. Chambers

1514 M. K. Neilsen

1514 C. M. Stone

1514 G. W. Wellman

1540 J. R. Asay

1544 E. D. Reedy

1544 G. D. Sjaardema

$1550 \mathrm{C}$. W. Peterson

1800 R. J. Eagan

1810 D. W. Schaefer

$1812 \mathrm{C}$. L. Renschler

$1813 \mathrm{~J}$. G. Curro

1813 D. Adolf

1813 P. B. Rand

1 13 R. R. Lagasse

2361 T. J. Williams

2364 J. F. Jones
2400 W. E. Alzheimer

2410 T. J. Young

2411 T. J. Young,actg.

2413 G. L. Cessac

2413 F. L. Gentry

2413 J. S. Arzigan

2413 M. D. Lucas

2470 J. L. Ledman

2472 J. A. Sayre

2472 M. W. Donnelly

2472 T. R. Guess (10)

2472 R. L. Myers

2472 K. B. Wischmann

2473 J. W. Munford

2476 F. P Gerstle Jr

2484 R. C. Reuter Jr

2500 G. N. Beeler

$2560 \mathrm{~J}$. T. Cutchen

2561 C. E. Spencer

2561 D. K. Morgan

2561 W. E. Neuman

2564 R. A. Damerow

2564 J. P. Brainard

3141 S. A. Landenberger (5)

3145 Document Processing for DOE/OSTI (8)

3151 G. C. Claycomb (3)

8240 C. W. Robinson

8241 G. A. Benedetti

8242 M. R. Birnbaum

8243 M. L. Callabresi

8310 D. L. Linder

8311 J. E. Costa

8311 R. E. Gott

8314 M. W. Perra

8523-2 Central Technical Files 

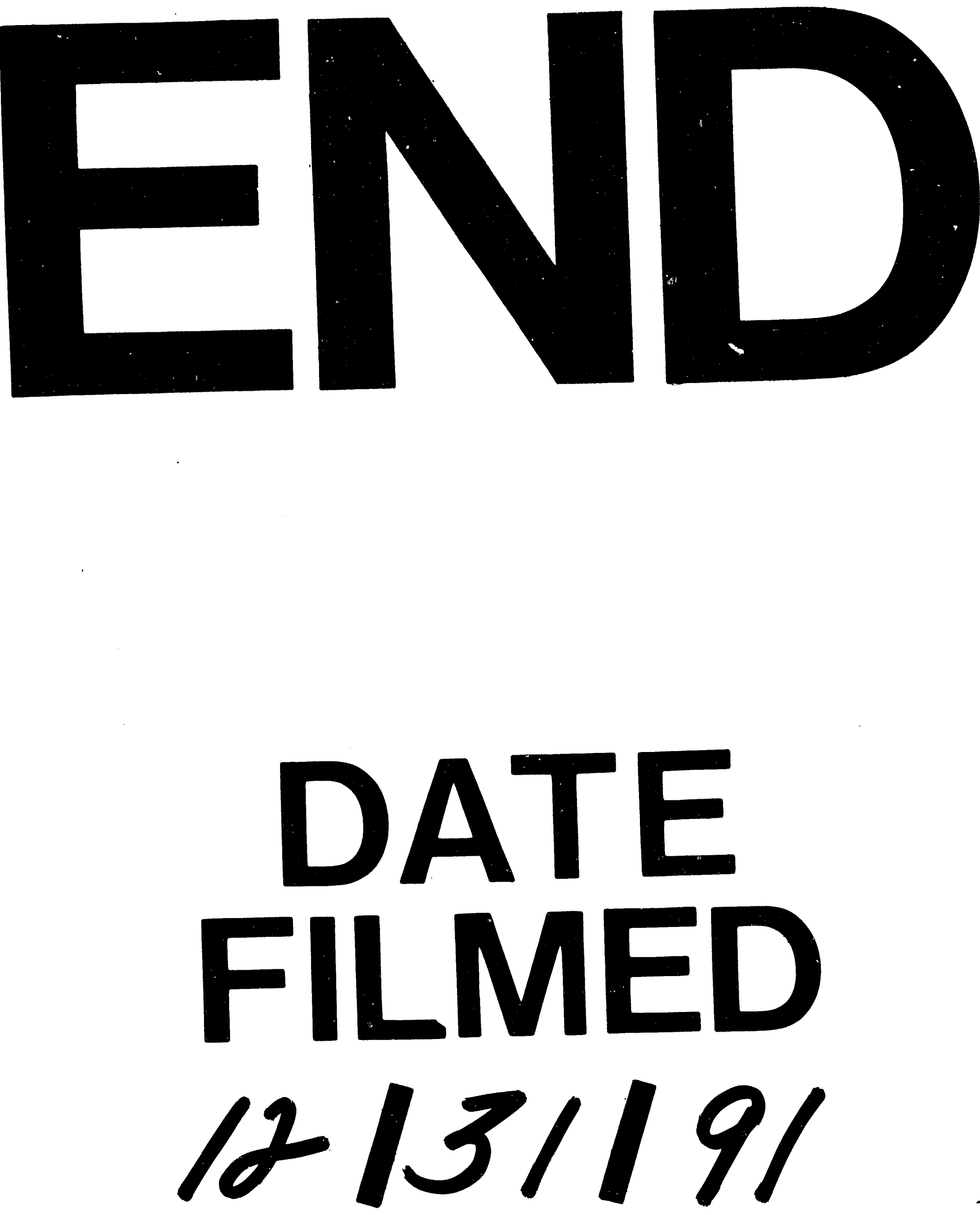